\title{
Care for the Caregiver Internet intervention for informal caregivers in Lithuania
}

\section{ieva Biliunaite}

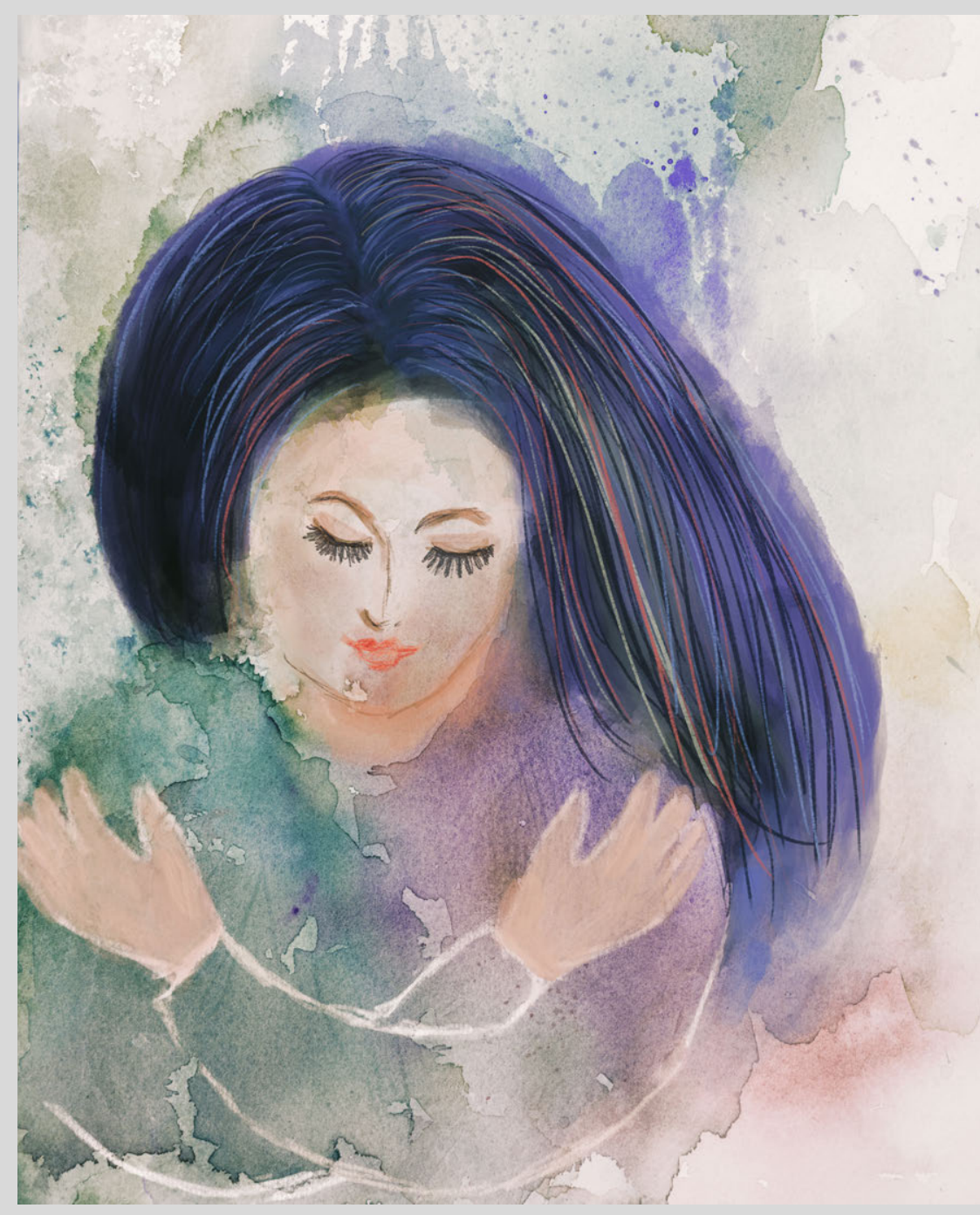



Linköping Studies in Arts and Sciences No. 831

Linköpings Studies in Behavioural Science No. 239

\section{Care for the Caregiver}

Internet intervention for informal caregivers in Lithuania

ieva Biliunaite

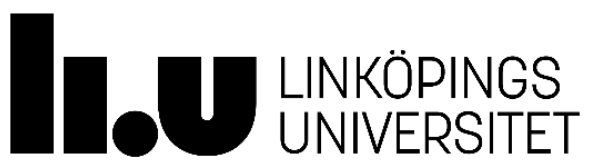

Department of Behavioural Sciences and Learning

Faculty of Arts and Sciences

Linköpings universitet, SE-581 83 Linköping, Sweden

Linköping 2022 
(C) ieva Biliunaite, 2022

Creative Commons Licence CC BY

Printed in Sweden by LiU-Tryck, 2022

ISBN 978-91-7929-186-o (print)

ISBN 978-91-7929-187-7 (PDF)

https://doi.org/10.3384/9789179291877

ISSN 0282-9800

ISSN 1654-2029

Cover by: Martin Pettersson, LiU-Tryck 
'The duty of children is to respect their parents, to take care of them in their old age, and to preserve their heritage.'

The Constitution of the Republic of Lithuania (Adopted by the citizens of the Republic of Lithuania in the Referendum of 25 October 1992)

'Vaikų pareiga - gerbti tėvus, globoti juos senatvẻje ir tausoti jų palikimą.'

Lietuvos Respublikos Konstitucija 1992 (Lietuvos Respublikos piliečių priimta 1992 m. spalio 25 d. referendume) 



\section{Abstract}

Informal caregivers are individuals who provide care for significant others in need of support due to frailty or illness. Informal caregivers often do not have prior caregiving experience and provide care in addition to their regular work and personal life demands. Being able to support a family member can be a rewarding but also a demanding task. Consequently, informal caregivers experience both positive and negative psychological health outcomes. Psychological support for informal caregivers can be delivered online. Online support interventions for informal caregivers vary in formats and target outcomes. Interventions based on the Cognitive Behavioural Therapy (CBT) principles are considered promising in providing psychological support.

The main goal of this thesis was to evaluate if Internet-based Cognitive Behavioural Therapy (ICBT) can be suited to provide Lithuanian informal caregivers with psychological support. In addition, a secondary aim was to collect information regarding Lithuanian informal caregiver characteristics, their experienced burden and support needs. To meet these goals, four research studies were conducted.

Study I was a cross-sectional online survey consisting of 38 items investigating informal caregiver characteristics, their support needs, and the COVID-19 pandemic impact on well-being. In addition, the 24-item Caregiver Burden Inventory (CBI) was included to access informal caregiver burden. A total of 226 individuals filled in the survey. The results indicated that informal caregivers in Lithuania experience a high caregiver burden and a need for more support. The majority of the informal caregivers did not identify COVID-19 to cause changes in their own or the well-being of the care-receiver.

Study II was a pilot randomized controlled trial (RCT) investigating the effects of ICBT on reducing informal caregiver burden and depression, anxiety, stress, and increasing the quality of life. A total of 63 Lithuanian informal caregivers took part in the trial. Participants were randomized to either the intervention or the wait-list control group. Moderate to high between-group effect sizes in favour of the intervention group were found, indicating ICBT's potential for providing psychological support for informal caregivers. 
Study III was a qualitative study with 23 participants from the pilot RCT trial. Participants were interviewed about their experiences of using the intervention. Data were analysed using the reflexive Thematic analysis approach. Following data analyses, four themes and 10 sub-themes were generated. Altogether themes and sub-themes provided insights into which aspects of the ICBT participants appreciated and aspects that could be improved further. In addition, certain personal and situational factors impacting informal caregiver well-being were identified and should be accounted for in further interventions development.

Study IV was a process evaluation involving previously unused participant data from Study II and novel data collected during a focus group discussion with eight stakeholders. The main goal of this study was to evaluate the suitability of ICBT for the Lithuanian informal caregiver population. Qualitative and quantitative data were collected and analysed using descriptive statistics, data categorization and a reflexive Thematic Analysis approach. Results indicated ICBT's content and format to be perceived positively by both informal caregivers and the stakeholders. Specific suggestions for the intervention's development were also outlined, such as allowing for personalization and improving the instructions on how to use it.

In conclusion, Study I indicated that informal caregivers experience a high burden and need more support. In turn, Studies II-IV provided evidence for ICBT's potential in providing psychological support for Lithuanian informal caregivers. Concerning future research studies, further development of the intervention should be considered, after which, an evaluation of its suitability should be once again conducted.

Key words: Informal Caregivers; Caregiver Burden; Internet Intervention; Digital Mental Health; Cognitive Behavioural Therapy; Internet-based Cognitive Behavioural therapy; ICBT; eHealth; mHealth. 


\section{Empirical studies}

I. Biliunaite, I., Kazlauskas, E., Sanderman, R., \& Andersson, G. (2022). Informal caregiver support needs and burden: a survey in Lithuania. BMJ Open, 12, e054607.

II. Biliunaite, I., Kazlauskas, E., Sanderman, R., Truskauskaite-Kuneviciene, I., Dumarkaite, A., \& Andersson, G. (2021). Internet-based cognitive behavioral therapy for informal caregivers: Randomized controlled pilot trial. Journal of Medical Internet Research, 23, e21466.

III. Biliunaite, I., Dumarkaite, A., Kazlauskas, E., Sanderman, R., \& Andersson, G. (2021). ICBT program for improving informal caregiver wellbeing: A qualitative study. Internet Interventions, 23, 100361.

IV. Biliunaite, I., Kazlauskas, E., Sanderman, R., \& Andersson, G. (2021). Process evaluation of internet-based cognitive behavioral therapy intervention for informal caregivers. Frontiers in Medicine, 8, 725510. 


\section{Abbreviations}

ADLs: Activities of Daily Living

ANCOVA: Analysis of Covariance

ANOVA: One-Way Analysis of Variance

AUDIT: The Alcohol Use Disorders Identification Test

BBQ: The Brunnsviken Brief Quality of Life Scale

CBI: Caregiver Burden Inventory

CBT: Cognitive Behavioural Therapy

GAD-7: Generalized Anxiety Disorder-7

IADLs: Instrumental Activities of Daily Living

ICBT: Internet-based Cognitive Behavioural Therapy

ITT: Intention-to-treat Principle

LEC: Life Events Checklist

MAR: Missing at Random

PHQ-9: Patient Health Questionnaire-9

PSS-14: Perceived Stress Scale-14

RCI: Reliable Change Index

RCT: Randomized Controlled Trial

WHO-5: The World Health Organization-Five Well-Being Index 


\section{Contents}

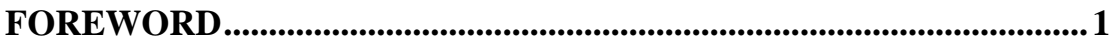

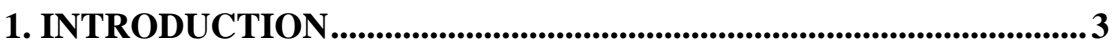

1.2. CAREGIVING OUTCOMES .............................................................. 4

1.2.1 Positive caregiving outcomes........................................... 4

1.2.2 Negative caregiving outcomes .........................................

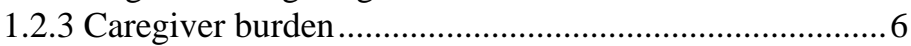

1.3 WHO IS AT RISK FOR NEGATIVE OUTCOMES? ......................................... 6

2. UNDERSTANDING INFORMAL CAREGIVING OUTCOMES .....9

2.1 TRANSACTIONAL THEORY OF STRESS AND COPING ………………........ 10

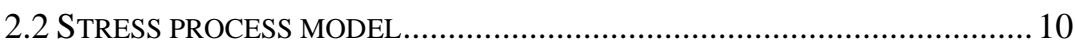

2.3 CAREGIVING STRESS AND APPRAISAL MODEL ........................................ 11

2.4 AN INTEGRATIVE FRAMEWORK ………………………................... 11

2.5 UNDERSTANDING POSITIVE CAREGIVING OUTCOMES............................. 12

3. INFORMAL CAREGIVER SUPPORT INTERVENTIONS.............13

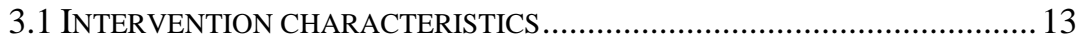

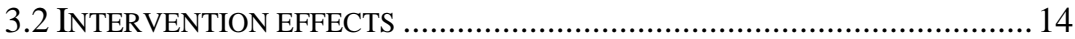

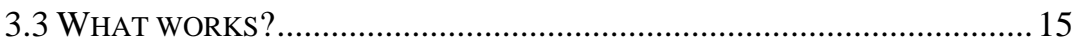

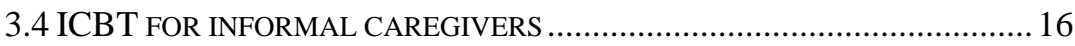

4. LITHUANIAN CULTURAL CONTEXT ........................................18

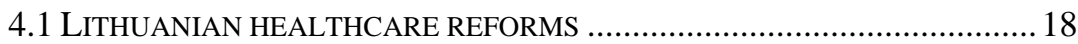

4.2 SUPPORT FOR INFORMAL CAREGIVERS............................................... 19

5. INTERNET INTERVENTIONS IN LITHUANIA................................21

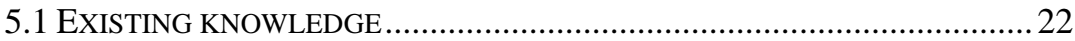

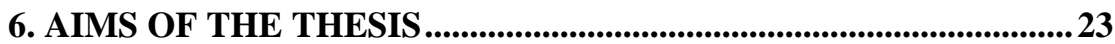

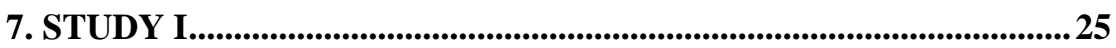

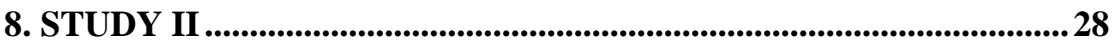

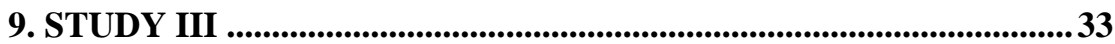

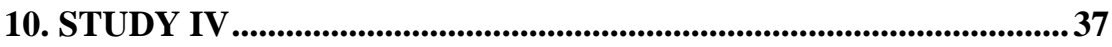

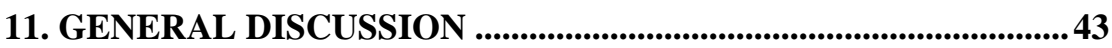

11.1. INFORMAL CAREGIVER CHARACTERISTICS........................................ 43

11.2. ICBT FOR INFORMAL CAREGIVERS: OVERALL FINDINGS..................... 44

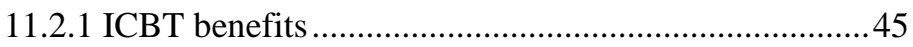


11.2.2 Further development of intervention. 46

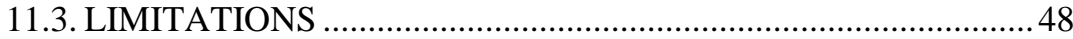

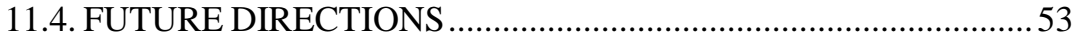

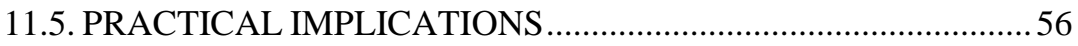

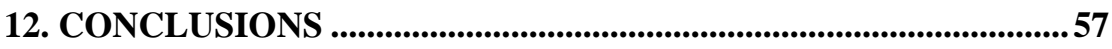

13. ACKNOWLEDGEMENTS.........................................................58

14. TRUMPA SANTRAUKA LIETUVIŠKAI ................................60

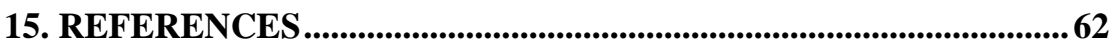




\section{Foreword}

Throughout my childhood and teen years, my grandmother was living together with us, in our parents' house. Since both of my parents were working and were frequently not at home, not long after me and my younger sister left for further studying, my grandmother moved to live with my aunt. There she spent her last years before getting hospitalized and leaving us on the 18th of July in 2020.

It was fun having my grandmother live with us while growing up. She would pamper me and my sisters, would help with homework, cook delicious meals. In my early memories, she was a very independent lady, very bright and active, a big fan of books and reading. She was always cheerful, caring and very loving. In the later years, she became less active and so my parents and aunt would often assist her with such activities as buying groceries or driving to the appointments. She also became quieter and more drawn to herself. We noticed that it was not always easy for her to find the right words for expressing her thoughts. In the last years, my parents and my aunt were highly involved in supporting my grandmother. Eventually grandmother had to be hospitalized due to the worsening of her condition.

Our family's story is one example of providing care for a beloved one. One example of supporting close family member throughout the years and experiencing the worst and the better of it. Even though each circumstance is unique, there are many, many other stories like ours.

It could be argued that caring for members of our families is imprinted in human nature. In some cases, such support might require individuals to perform certain skills or training requiring procedures or spend periods of time and invest personal resources in helping the ones in need. In some circumstances, support provision might even result in worse health for the one who is providing care. Yet, numerous individuals worldwide choose or are faced with the need to provide care. Knowing that such a position might be demanding, providing them with psychological support is necessary.

In the last few years, I had the honour to learn about other caregiver experiences, their needs, and the difficulties that they face. Therefore, in this thesis, I will share the results of this work, conducted in collaboration with a group of scientists across three European countries. 
I hope that the research work described in this thesis will not only enrich the existing knowledge but also inform and inspire future research into the informal caregiving field. 


\section{Introduction}

Informal caregivers can be described as individuals who voluntarily provide care to persons with frailty, illness or other long-lasting health or social needs (Tur-Sinai et al., 2020). The informal caregiver definition also specifies that the care should be provided on at least a weekly basis and that it should be performed outside a professional or formal framework. Even though informal caregiving is suggested to affect most people at some point, the actual prevalence of informal caregiving varies. Recent data estimates show that the proportion of informal caregivers among adults is approximately $13 \%$ in countries such as Spain and Portugal and $22 \%$ or more in Belgium, Luxembourg, and Denmark (Tur-Sinai et al., 2020). Women tend to provide care more often than men (Tur-Sinai et al., 2020) though the prevalence of men informal caregivers have been increasing over the last years (Calvó-Perxas et al., 2018). Moreover, care provision is more prevalent among unemployed, religious women between 50 and 59 years of age (Verbakel et al., 2017). Also, more common among individuals with higher rather than lower or poor education levels (Tur-Sinai et al., 2020). However, it should be outlined that informal caregiving occurs in various age groups, ethnicities, and among individuals from diverse socioeconomic backgrounds. The carer profiles will potentially become even more diverse in the future due to the increase in the demand for informal care.

Caregiving, in turn, could be defined as a process of providing holistic (emotional, social, physical, and mental) support (Hermanns \& MastelSmith, 2012). This definition could be expanded by outlining that caregiving is often an unpaid act that might last from a period of days to several years (Roth et al., 2015). One aspect that distinguishes caregiving from social support is that informal care provision often stems from the strong feeling of obligation or love towards the person in need of care (Revenson et al., 2016). That is, informal care recipients are often family members or siblings that have a close connection to the informal caregiver. In addition, as opposed to social support, caregiving is more unidirectional. It involves support with various tasks extending beyond the frame of the typical social support in a relationship (Revenson et al., 2016).

Caregiving can be described as a journey or as a dynamic process (Revenson et al., 2016). That is, the amount of assistance that is needed, own competency in providing the care, and other factors vary in time and intensity, which altogether influence the caregiving experience. To this date, there is no universally accepted gold standard measure for evaluating 
caregiving intensity. One of the more common ways is to evaluate how many hours per day, week, or month an informal caregiver spends on care provision. To give an example, individuals providing care for 11 or more hours per week were previously identified as intensive caregivers, as opposed to the ones who spend less time on care provision weekly (Verbakel et al., 2017). Another way to evaluate the intensity of informal caregiving is via the number, complexity, and frequency of tasks that the individual performs in providing care. Such tasks can be broadly described as activities of daily living (ADLs) and instrumental activities of daily living (IADLs). The latter includes activities such as maintaining general hygiene (for example: cutting nails) as well as eating, moving, and dressing. In turn, IADLS include activities such as doing laundry, cooking, taking medication and managing finances. Overall, higher caregiving intensity could be linked to the higher number of activities that the care-receiver needs assistance with, performed on a higher frequency. It is suggested that informal care provision is becoming increasingly demanding and that informal caregivers are sometimes required to perform very complex tasks, such as medical equipment management (Reinhard et al., 2015).

\subsection{Caregiving outcomes}

Early research articles investigating caregiving consequences for the caregiver were published around the time of the 1980s (Johansson, 1991). It was recognised that caregiving could result in positive as well as negative mental health outcomes for the caregivers. Since then, a great number of research studies have been conducted documenting caregiving experiences as well as investigating the reasons behind caregiving. In this thesis, I primarily focus on the psychological caregiving outcomes. In general, such outcomes could be divided into two broad groups: the negative and the positive.

\subsubsection{Positive caregiving outcomes}

Informal caregivers can experience a range of positive outcomes that could be further described as transformative aspects of caregiving (Revenson et al., 2016). Caregiver gains is a term that could be used to define the extent to which the caregiving experience is benefiting the informal caregiver (Kramer, 1997). In other words, the rewarding experience, or positive feelings that individuals experience due to informal caregiving. In addition to being perceived as a positive outcome, caregiver gains can also play a role as a coping mechanism helping an individual deal with the daily demands of caregiving. Some other commonly mentioned positive outcomes include life satisfaction and positive affect (Marino et al., 2017). Also, experiencing gratefulness for the time spent with the care-receiver (Parveen \& Morrison, 
2012), a greater sense of inner strength (Chen \& Greenberg, 2004), and personal growth and feelings of reward (Li \& Loke, 2013). Moreover, some caregivers even report that they would be less happy if someone else were to provide care instead of them (Brouwer et al., 2005). Altogether these findings indicate that informal caregiving can have meaningful and beneficial effects for the caregivers.

\subsubsection{Negative caregiving outcomes}

Negative mental health outcomes following care provision is a widely investigated topic in informal caregiving research. To name a few examples, informal caregivers were found to have an increased risk for developing depression (Geng et al., 2018), symptoms of anxiety (Loh et al., 2017), lower self-efficacy (Pinquart \& Sörensen, 2003) and stress (Schulz \& Sherwood, 2008). Previous research has also shown that informal caregivers might experience negative physical health outcomes, such as an increased risk for cardiovascular disease (Capistrant, Moon, Berkman, et al., 2012) and hypertension (Capistrant, Moon, \& Glymour, 2012).

One of the more interesting and contradictory research findings comes from the studies investigating the risk for mortality among caregivers. Some studies have found increased mortality in caregivers experiencing high strain (Perkins et al., 2013). In contrast, others have reported mixed results (Vlachantoni et al., 2013) or found that caregivers have a lower mortality risk than non-carers (O'Reilly et al., 2015). Mehri and colleagues (2021) recently conducted a meta-analysis of longitudinal population-based studies to evaluate caregiver mortality in the light of two theories: stress theory and the healthy caregiver hypothesis. According to the latter, healthier individuals are more likely to choose to provide care (Bertrand et al., 2012). Moreover, caregiving is proposed to keep caregivers healthier and more fit than noncarers. In turn, the stress theory states that caregiving could be viewed as a chronic stressor that over time increases the mortality risk for the caregivers (Mehri et al., 2021). The study findings indicated that the combined effect of informal care resulted in mortality benefits for the informal caregivers providing support for the healthy caregiver hypothesis (Mehri et al., 2021). However, after several covariates were accounted for (such as the country of residence or the definition of informal caregiving used in the study), the mortality advantage was no longer present, leaving the discussion regarding the association between mortality and caregiving open. 


\subsubsection{Caregiver burden}

The caregiver burden is a well-documented negative caregiving outcome. It can be defined as a built-up of various care-related psychological, financial, and physical demands (Revenson et al., 2016). The caregiver burden is further conceptualized into a subjective and objective burden. The objective burden concerns the magnitude of the care provision tasks. That is the frequency and the number of tasks for which support is needed. Some examples include providing the care-receiver with support in bathing, cooking, eating or medication intake. Objective burden also encompasses tasks that the informal caregiver takes over from the care recipient once an individual can no longer perform them oneself (e.g., managing finances or performing home repairs). Lastly, the magnitude of the objective burden could also be reflected in the number of hours or days that the informal caregiver is involved in the care provision. In turn, subjective burden represents the affective domain of the caregiver's experience (Zarit et al., 1986). That is, how informal caregivers perceive various aspects of their situation and the feelings induced by such perceptions. Consequently, subjective burden addresses both negative as well as positive experiences (Nijboer et al., 1999). Altogether, it must be emphasized that caregiver burden is a multidimensional and individualized experience, for which individuals' perceptions of the circumstances play an important role.

\subsection{Who is at risk for negative outcomes?}

Caring for an individual with dementia, lacking internal or external resources and having pre-existing health conditions are examples of risks for experiencing negative caregiving outcomes (Roth et al., 2015). Elliott and Parker (2012) summarized certain demographic (lower education level, older age, worse health, and unemployment), personal (experience of depressive symptoms and distress, substance abuse and poor coping and problem-solving skills) and interpersonal (poor marital quality, lack of social support, interpersonal conflict, and impaired prior relation to the care-receiver) characteristics that put informal caregivers at higher risk of experiencing negative caregiving outcomes. This list could be extended by adding that intensive caregivers, who provide care for 11 or more hours per week, are more prone to experience reduced mental well-being (Verbakel et al., 2017). The relation with the care-receiver might also have an impact on caregiving outcomes. Spousal caregivers have been found to experience worse physical and psychological health than individuals providing care for adult children or children-in-law (Pinquart \& Sörensen, 2003). Disease-related variables should also be mentioned. For example, a greater likelihood of strain has been found to occur in informal caregivers for individuals with frontotemporal 
dementia as these individuals tend to experience more neuropsychiatric symptoms and behavioural problems (Brodaty \& Donkin, 2009). Lastly, culture and ethnicity also make a difference as factors such as social expectancy of care and social norms of support seeking influence caregiving outcomes (Pinquart \& Sörensen, 2005).

Gender differences in the caregiving outcomes should not be neglected. In addition to making up the larger part of informal caregivers, women caregivers tend to experience worse psychological health outcomes than men. To name a few examples, women caregivers are more prone to experiencing depressive symptoms (Verbakel et al., 2017), higher levels of subjective burden (del-Pino-Casado et al., 2012) and lower levels of physical health (Pinquart \& Sörensen, 2006a). Distress can be mentioned as another example. A study found that in couples affected by cancer, women experienced more stress than men, irrespectively of their role (being diagnosed with cancer versus being the partner of the person with the diagnosis) (Hagedoorn et al., 2008). One explanation could be that women tend to provide more complex and intensive care (Navaie-Waliser et al., 2002). That is, providing care for a wider range of ADL and IADL activities and complex tasks such as medical equipment use and medication intake. At the same time, it should not be presumed that male caregivers do not experience negative outcomes. It was recently documented that even though women were more likely to report severe depression following caregiving, increased anxiety was reported by both genders (Bhan et al., 2020). In another recent study, it was found that the start of the care provision was followed by different consequences for the sexes; while women were found to experience an increase in negative affect, men were found to experience an increase in depressive symptoms and loneliness (Zwar et al., 2020). Consequently, it can be concluded that certain gender differences exist in the experience and outcomes of caregiving.

Several other concepts can explain negative psychological health outcomes for informal caregivers. One of such is called activity restriction and refers to the disruption of the usual activities of an individual due to the need to provide care (Revenson et al., 2016). Activity restriction can apply in many areas of the caregiver's life. For example, one might have less time for engaging in hobbies or socializing, doing housework, or might need to make changes in own employment, such as reducing the hours spent at work. Therefore, it is not difficult to imagine that such a change in the otherwise usual routine might leave caregivers feeling strained. In cases where changes in employment must be made, care provision might impact on worsening financial situation for the caregivers. The so-called sandwich caregivers, who take care of underage 
children and provide informal care, might be vulnerable to the caregiver burden (Prevo et al., 2018).

Caregiving is a continuous activity that could last for several years. Therefore, the time frame is a significant element in accounting for the caregiver's wellbeing. There are two main views to explain caregiving outcomes over time. The first one proposes that the burden worsens over time due to the increasing challenges and is referred to as the caregiver strain or the wear and tear hypothesis (Townsend et al., 1989). Evidence for this hypothesis comes from studies that found long-term caregivers, providing care for two or more years, to experience an increase in depressive symptoms and a decrease in wellbeing and quality of life (Barnett, 2015; Rafnsson et al., 2017). The second view suggests that the caregiving burden should reduce once the caregiver adapts to the new circumstances, and it is referred to as the adaptation hypothesis (Revenson et al., 2016). The adaptation hypothesis is the opposite of the caregiver strain hypothesis. It suggests that caregiving demands are the highest and hence the most burdensome at the start of the care provision and should decrease over time once the individual adapts to the circumstances (Revenson et al., 2016). One example in support of this hypothesis is a study by Bookwala (2009) in which male caregivers were found to experience a decrease in depressive symptoms over time. Overall, it might be difficult to conclude which of these two opposing hypotheses most accurately depict caregiving outcomes over time. It could nevertheless be proposed that outcomes might depend on the individual cases and might change or fluctuate over time. 


\section{Understanding informal caregiving outcomes}

While it is evident that care provision can be as difficult as it can be rewarding, why does one choose to become an informal caregiver? The dedication to becoming an informal caregiver often stems from the feeling of obligation, responsibility, and love towards the person in need of support. Naturally, when faced with similar circumstances, not all individuals choose to provide care. According to the Informal Care Model by van Groenou and De Boer (2016), several determinants exist on an individual level, influencing one's choice to engage or abstain from care provision. In their proposed model, an individual initially must identify the need for care. Then, based on various factors such as perceived barriers to the care provision or attitudes and norms of reciprocity, intentions regarding the care provision are formed. Lastly, in the model, the final decision of whether to engage in care provision is influenced by the external conditions that impede or facilitate care provision. Some examples of such conditions are family context and the availability of community care. Altogether it could be summarized that according to the Informal Care Model, individuals' decision to become an informal caregiver depends on normative beliefs, general attitudes, relation to the care-receiver, social context, existing policies and perceived barriers and facilitators for the care provision (van Groenou \& De Boer, 2016).

Evolutionary theory may help to explain why individuals choose to provide care. For example, Brown and Brown (2006) proposed a Selective Investment Theory according to which human social bonds evolved for the promotion of high-cost altruism. Brown and Brown (2014) further proposed that the dedicated neurobiological systems that evolved to motivate helping behaviour also led humans to become natural caregivers. Their argument also expressed criticism against focusing on the negative caregiving outcomes instead of caregiving related enhancements, which, in turn, could have been an incentive for the development of these neurobiological mechanisms.

Over the years, several theories have been used to explain caregiving impact on the caregiver. Initially, researchers aimed to explain the occurrence of negative caregiving outcomes. The latter has shifted in the last decades, with increasing research efforts focused on better understanding and fostering positive caregiving experiences. Still, the caregiving frameworks developed in the last two decades of the 19th century are relevant in understanding the caregiving outcomes and are still applied in caregiving research. I will 
shortly review a few of these theoretical frameworks in the following paragraphs.

\subsection{Transactional theory of stress and coping}

A few decades ago, Lazarus and Folkman (1984) introduced a theoretical framework that is still widely implemented in caregiving research. The framework is named the Transactional theory of stress and coping and is focused on understanding the experience of stress. More specifically, it outlines an individual's appraisal as a driving force in the experience of stress. In the framework, a distinction is made between the different types of appraisals: primary, secondary, and reappraisal. Primary appraisal is described as the evaluation or assessment of the stressor as either benignpositive, irrelevant, or stressful. The secondary appraisal, in turn, is defined as a complex evaluation process about what actions must be taken to deal with the situation. Lastly, reappraisal refers to the re-assessment of the initial appraisal based on the new input. The main idea behind the theory is that stress occurs less due to the stressful event or situation and more due to an individual's perception of the event or the situation. In other words, the same situation/stressful event is likely to be perceived differently by different individuals. Lazarus and Folkman (1984) further proposed that stress can be reduced by improving an individual's coping strategies. These ideas were further adapted by Lawton et al. (1989) and applied in the caregiving context to conceptualize the Caregiving appraisal model.

\subsection{Stress process model}

The Stress process model was developed by Pearlin and colleagues (1990) based on the work with the caregivers of individuals with Alzheimer's. Four main domains were distinguished in this model: 1) background and context, 2) stressors, 3) mediators, and 4) outcomes of the stress. These domains are proposed to consist of several components. To give an example, the second domain, stressors, is divided into primary stressors, secondary role strains and secondary intrapsychic strains. The primary stressors category consists of two sub-categories: objective indicators (e.g., behavioural problems) and subjective indicators (e.g., overload). The secondary intrapsychic strains also contain two sub-categories: global (e.g., mastery) and situational (e.g., loss of self). Thirdly, the category of secondary role strains includes factors such as family conflict and economic problems. Overall, one of the main goals of the model was to illustrate that multiple factors and mediating processes interact in the experience of stress. Similar to the model by Lazarus and Folkman 
(1984), Pearlin et al. (1990) outlined coping as an important factor in individuals' apprehension of caregiving circumstances.

\subsection{Caregiving stress and appraisal model}

The model by Yates et al. (1999) extends the ideas of the previous models by Lawton et al. (1989) and Pearlin et al. (1990). This model, named as Caregiving stress and appraisal model, includes five elements: 1) primary stressors (cognitive impairments, functional disability, and problem behaviours), 2) primary appraisal (hours of informal care), 3) mediators (quality of the relationship, emotional support, mastery and formal services), 4) secondary appraisal (overload) and 5) outcome (depression). One of the most important aspects of this model is that it distinguishes between two separate forms of appraisal. That is, between the primary appraisal indicated as hours spent for informal care, and secondary appraisal indicated as an experience of overload or burden. According to this model, care-receivers needs, and the time caregiving requires (in combination with mediating variables such as quality of the relationship) might result in the feeling of overload, which can then lead to feelings of depression (Yates et al., 1999). Importantly, the model suggests that the overload/burden is a product of the caregiver's perception. Therefore, it is the appraisal of the burden that is suggested to impact the development of depressive symptoms.

\subsection{An integrative framework}

Since the early research in the 1980s and 1990s, further efforts were made in conceptualizing and measuring caregiving and its outcomes. One recent example by Revenson et al. (2016) is an integrative framework for studying caregiving in an illness context. This framework presents a general structure illustrating the caregiving process and factors that should be considered. More specifically, the framework encompasses temporal and sociocultural contexts, the health challenge, and the dyadic interaction between the caregiver and the care recipient. In this framework, caregiving is viewed as a demanding situation requiring one to perform objective tasks (the health challenge). Positive or negative caregiving outcomes are suggested to occur based on the caregiver's appraisal of these tasks and are moderated by various caregiving related characteristics, such as illness severity as well as the broader socio-cultural context (e.g., existing caregiving norms) (Revenson et al., 2016). The caregiver-care-receiver dyad is given an important role in the caregiving experience, with the appraisal of both members of the dyad having an impact on how it is perceived. 


\subsection{Understanding positive caregiving outcomes}

Finally, Carbonneau et al. (2010) should be mentioned for developing one of the first conceptual frameworks for understanding positive caregiving outcomes. This model consists of several components which are suggested to be interdependent but at the same time function together in reinforcing positive caregiving experiences. To start with, it contains three main domains: 1) caregiver's feeling of accomplishment, 2) meaning of the caregiver's role in daily life, and 3) quality of caregiver/care-receiver daily relationship. These domains are placed at the centre of the framework and depict the main sources of positive outcomes in caregiving. In addition to the central domains, the model also includes two determining factors (daily enriching events and own sense of self-efficacy). Informal caregiver's self-efficacy is suggested to play a central role in generating enrichment of events which, in turn, leads to positive outcomes for the caregiver in one of the three central domains and, in this way, encourages further involvement in the care provision. 


\section{Informal caregiver support interventions}

In an early review, Biegel et al. (1991) reported on 138 studies that had evaluated various interventions providing support for informal caregivers caring for individuals with a range of symptoms. Biegel and colleagues (1991) characterised the interventions into three main groups: interventions in the form of 1) support groups, 2) education, or 3) direct service or clinical interventions. The aims of the different types of interventions were slightly different, from offering emotional support to providing caregiving-related information. However, all of them aimed at supporting informal caregivers in their roles. Since that time, research has focused on developing, evaluating, and implementing various support interventions for informal caregivers. Existing interventions cover a wide range of techniques, formats and delivery methods and are aimed at various groups of caregivers and caregiving outcomes.

\subsection{Intervention characteristics}

Interventions for informal caregivers can be target group-specific (e.g., caregivers of breast cancer survivors) or applied to broad groups (e.g., adult caregivers). Also, they can be targeted for individual informal caregivers, for the caregiver-care-recipient dyad or the whole family. Interventions for informal caregivers can focus on specific symptoms, such as, for example, grief and coping with the loss of the care-receiver (Moss et al., 2021) or improving the quality of the sleep of the caregivers (Pignatiello et al., 2021). Also, it can be aimed at assisting with specific tasks, such as medication management (Sawan et al., 2021). At the same time, interventions can target broader goals, such as encouraging positive caregiving outcomes (Quinn \& Toms, 2019). Quality of life, depressive symptoms, burden, emotional distress, and self-efficacy have been some of the most targeted outcomes in the informal caregiver intervention research (Pendergrass et al., 2015). Additional factors could also be measured, such as intervention intensity, which could be defined as the time required for engaging with the intervention as well as its duration. To give an example, some interventions might require informal caregivers to attend one or more weekly sessions for some time while others, such as online interventions, would require engaging with the intervention for at least a certain amount of time daily or weekly. Lastly, different ways of delivering interventions exist. To name some examples, interventions might be offered face-to-face or online, over the telephone, video, or offer a combination of a few of these methods. 
Initially, most of the interventions for the informal caregivers have been delivered face-to-face. However, over recent years there has been an increase in the development of remotely delivered interventions conducted, for example, via the telephone or the internet. Even though many terms exist to refer to these interventions, such as web-delivered interventions, mHealth, and eHealth, among others (Smoktunowicz et al., 2020), I will further refer to them as internet interventions. One reason to consider internet interventions is that they may provide informal caregivers with more flexibility and might be less costly. The COVID-19 that took over the world in 2019 could also be viewed as another reason for the development of internet interventions as human mobility, and the availability of face-to-face services decreased dramatically during the pandemic.

Support interventions for informal caregivers can be categorized in different ways. To give an example, interventions could be grouped based on their dominant treatment orientation and components (Pinquart \& Sörensen, 2006b). One example could be treatments based on Cognitive Behavioural Therapy (CBT) principles with possible components including psychoeducation, emotional support, cognitive rehabilitation, or mindfulness (Lee et al., 2020). A broader generalization is also possible by dividing the interventions into the ones focused on one component (e.g., information provision) as opposed to multiple components (e.g., information provision and support or monitoring (Ploeg et al., 2017).

\subsection{Intervention effects}

It is difficult to draw any firm conclusions about the effects of the support interventions for informal caregivers. Some of the reasons for this are the heterogeneity of the existing interventions as well as the heterogeneity of the different target groups, and the variety of outcomes that are being assessed (Revenson et al., 2016). Despite that, several reviews and meta-analyses have been published evaluating intervention effects. Current evidence suggests that CBT approaches are among the most successful (Lee et al., 2020; Wiegelmann et al., 2021), especially in reducing anxiety and depression. These findings were found to account even for less therapist-demanding CBT (either self-help or supported by non-professionals or professionals, but for a very short time only) (Kaddour et al., 2019), and irrespectively if it is delivered online or face-to-face (Kishita et al., 2018). In the case of internet interventions, interventions aimed at information or education with or without professional support and with combined peer and professional support were previously found to be the most promising for supporting informal caregivers (Sherifali et al., 2018). 
In terms of specific intervention outcomes, the findings are inconsistent. Even though depressive symptoms and caregiver burden are some of the most assessed outcomes, the findings are mixed. That is, research findings indicate both positive as well as no effects following intervention use (Wasilewski et al., 2017). In addition, some studies suggest worsening of the caregiver burden (Cherak et al., 2021). Similar findings could be observed for other outcomes, such as the quality of life, with studies reporting both an increase as well as no changes in the quality of the life of the informal caregivers following the intervention use (Revenson et al., 2016). It should be outlined that most of these findings represent the short-term effects (Cherak et al., 2021; Lee et al., 2020; Wiegelmann et al., 2021) and are focused on the specific group of informal caregivers (e.g., caregivers of individuals with dementia) that altogether limits the generalizability and further estimation of treatment effects.

\subsection{What works?}

There is some knowledge about the active ingredients of interventions that influence the change in the informal caregiver well-being. To provide some examples, in their study exploring the working mechanisms of the interventions for dementia caregivers, Van't Leven and colleagues (2018) identified empowerment to be at the core of what participants experienced as beneficial. They suggested that aspects such as self-mastery should be focused on to increase the benefits for the informal caregiver and the overall dyad. Another example comes from a study evaluating the effects of the anger and depression management intervention for women informal caregivers caring for an individual with dementia (Coon et al., 2003). Results showed mediating effects of self-efficacy for controlling upsetting thoughts and changes in depression and hostility for the informal caregivers. Some recent findings also provide evidence for self-efficacy, most particularly concerning the problem-solving skills and initiative for taking action in mediating the symptoms of depression (Lambert et al., 2021). Behaviour change techniques such as problem solving, stress management and human support have also been outlined as potentially effective in increasing caregiver well-being (Guay et al., 2017). Altogether, these research studies provide valuable insights into the potential working mechanisms of interventions for informal caregivers. However, more knowledge is needed for distinguishing which intervention components are responsible for the change in the caregiver outcomes. 


\subsection{ICBT for informal caregivers}

Internet-based Cognitive Behavioural Therapy (ICBT) could be defined as a CBT intervention that is adapted for the online setting and can be used via a computer, mobile phone, or any compatible device with internet access. In ICBT, content is divided into separate modules that address different topics, such as problem solving, thought processes and behavioural activation. Within each module, the content is divided into psychoeducational information aimed to introduce and provide education on the topic, which is then followed by examples and exercises for the participants. The content is often based on the text but can also include pictures, video recordings, and voice recordings. Dependent on the target population, the length of the interventions can vary from five to 15 weeks (Andersson, 2016). In addition, ICBT can be structured as a pure self-help intervention, or it can include therapist support. In the latter case, different variations are possible, but therapists often engage with the users via the messaging platform in the program. Such engagement is meant to provide users with an opportunity to receive feedback for their conducted exercises, allow asking questions and receive encouragement or guidance when necessary. The therapists, in turn, can be either trained mental health professionals or, as it is common in research trials, students in their final year of the clinical psychology training program (Andersson, 2015). Lastly, interventions can either be disorderspecific, otherwise referred to as tailored or address a wider range of symptoms. Respectively, interventions in the latter group are referred to as transdiagnostic (Schaeuffele et al., 2021). The ability to address comorbidities could be suggested as one of the main benefits of transdiagnostic treatments.

There are examples of internet intervention studies for informal caregivers that have incorporated CBT components (e.g., Beauchamp et al., 2005; Blom et al., 2015; Kajiyama et al., 2013). However, despite ICBT acceptability and efficacy in treating depression and anxiety (Etzelmueller et al., 2020) as well as other mental health and somatic disorders (Carlbring et al., 2018) in adults and adolescents, less is known about its suitability for supporting informal caregivers. To my knowledge, a research study by Meichsner et al. (2019) is one of the few examples evaluating guided ICBT's efficacy and acceptability for informal caregivers. In their study, an existing CBT intervention was adapted into the ICBT format. The intervention was evaluated following a randomized controlled trial with 39 dementia caregivers. Results highlighted the potential of the intervention, with participants expressing overall high satisfaction with ICBT. Unfortunately, I was not able to locate any follow-up trials further evaluating the suitability of the intervention. Some other ICBT evaluation projects for the informal caregivers are also underway, one 
example being SOSteniamoci intervention for Italian caregivers (Semonella et al., 2020) which, is currently in the preparatory stage. Altogether, ICBT effectiveness in treating psychiatric as well somatic conditions and lack of existing knowledge in the informal caregiving field encourages further research into its suitability. 


\section{Lithuanian cultural context}

Caregiver needs and suitability of support options should be evaluated in the context of existing cultural, demographic, and other specific factors. Some of the examples of important aspects to consider are attitudes towards care provision, availability of formal care and existing support services for the informal caregivers. Hence, to identify the most suitable support options for the caregivers, each country or even smaller region should be considered separately (Plöthner et al., 2019). Yet, there is little research evidence about how certain cultural factors influence intervention use and its effects (Revenson et al., 2016).

In this thesis, I focus on the Lithuanian cultural context. To understand the current state of the healthcare system in Lithuania, certain historical aspects should be discussed. During the period of the Soviet annexation between 1940 and 1990, a Semashko healthcare system model was implemented, which was based on a centralized system where patient care was to be provided by the district physicians (Murauskienè, 2021). The centralized healthcare system was also compromised of parallel healthcare systems, and the overall focus of the patient care was placed on institutional care. Over the years to follow, the system was extended to increase the number of hospital beds and the healthcare staff. Despite this, the healthcare infrastructure during this period was found to be functioning poorly (Murauskienè, 2021).

\subsection{Lithuanian healthcare reforms}

With the restoration of independence in Lithuania in 1990, several healthcare reforms took place. These reforms focused on decentralizing the healthcare system, providing the general practitioners with a position as gatekeepers for access to healthcare, as well as introducing compulsory National healthcare insurance policies (Murauskiene et al., 2013). In addition, one of the following and more recent goals was to integrate social and healthcare systems (Kudukyte-Gasperè \& Jankauskiene, 2015). The integrated model should have offered individuals an easier way to access the services. However, there is still a fragmentation of the health and social care services with two different institutions managed by the two separate ministries. Some services, such as nursing, provided by the two institutions are similar and even overlap. However, the financial reimbursement differs, with services in the healthcare sector being priced higher than those in the social domain (Poškute et al., 2021). This does not only make it more difficult for the informal caregivers to receive the best possible support needed but also causes tensions 
between the institutions. It should also be mentioned that in recent years there has been a growth of various non-state institutions (NGOs), or business institutions aimed at long-term care provision. However, findings indicate that despite the growth, a shortage of such services remains (especially in rural municipalities) and that the public, as well as the policymakers, do not view them as entirely serious (Poškutè et al., 2021).

In practice, long term care provision in Lithuania relies on institutional care. Based on the overview presented by Murauskienè (2021), there are two main nursing and long-term care provision options. Insured individuals can use the services of the nursing hospitals (also referred to as hospice or palliative care hospitals) that are integrated into the healthcare facilities for up to 120 days per year. This is the number of days that is compensated for a given individual. Another option is to receive support from the family nurses, who attend and provide the services in the home of the person in need of care. Certain requirements must be met and officially confirmed by the relevant regional institution to receive any of the two options. Overall, the nursing home and the day-care services were previously described as underdeveloped, offering limited support, and covering a small portion of highly dependent individuals (Žalimienè et al., 2020). The lack of services might be partly explained by the general lack of nursing hospitals and nursing personnel across the country (Poškutè et al., 2021).

The social care system in the country has institutionalized care for patients as an alternative to nursing healthcare hospitals. However, even with the growing number of these care institutions, there is a significant lack of social services in institutionalized care. Thus, these services are mostly used by individuals who do not have family members, relatives, or other caregivers. Very often, these services are utilized by the elderly with health issues whose children have been emigrated abroad.

\subsection{Support for informal caregivers}

How do the existing policies affect informal caregivers? Firstly, due to the limited availability of formal support for persons in need of care, individuals might have fewer options when deciding to become informal caregivers and later when receiving care-related support. Once already providing care, informal caregiver possibilities for respite can be very limited. Established in 2007, respite services were found to be only present in certain municipalities and cover only a small proportion of individuals. In turn, existing labour market policy measures in Lithuania were previously described as minimalistic and insufficient for enabling informal caregivers to balance their 
work, private life, and caregiving duties (Žalimienė et al., 2020). Based on this, it could be summarized that existing policies do not provide caregivers with much flexibility. In addition, existing support measures are very limited and could therefore put informal caregivers at a higher risk of developing negative psychological health outcomes.

Mental health services in Lithuania could be described as relatively easily accessible since there is no need for referrals, and such services can be approached directly. However, mental healthcare-seeking is suggested to be impeded by the presence of stigmatic attitudes towards mental illness (Doblyte, 2020). Despite being accessible, such services were also found to be not necessarily acceptable, with some individuals previously reporting a lack of trust in the healthcare providers (Doblyte, 2021). Furthermore, mental health services are mostly focused on diagnosing and treating mental health disorders. Therefore, individuals with a caregiving burden and with anxiety or depression but not meeting full diagnostic criteria for mental disorders would not receive treatment.

Existing research regarding Lithuanian informal caregiver well-being and the existing psychological support options is scarce. The literature is almost exclusively based on the qualitative findings and focused on informal caregivers of a specific group of individuals, such as, for example, individuals with dementia. Lastly, to the best of my knowledge, no previous studies were conducted for investigating the suitability of the internet intervention providing Lithuanian informal caregivers with psychological support. 


\section{Internet interventions in Lithuania}

Informal caregivers represent a growing part of the population that dedicates a substantial amount of time and resources for caregiving. In Lithuania, where existing policy and psychological help options are scarce, further efforts should be focused on developing and implementing support measures for informal caregivers. One option could be to provide psychological support over the internet. Some of the motivation behind this is the higher flexibility in the possible use of such intervention as compared to face-to-face support. In addition, internet interventions do not require individuals to travel to appointments and can be used from the comfort of their own homes. Moreso, since such interventions can offer more anonymity, they could be attractive to individuals who would not reach out to psychological help professionals due to the mental health stigma. As reflected in chapter three, ICBT has been found to be effective in supporting individuals with various psychological health complaints. Therefore, ICBT could also be proposed to have the potential in supporting informal caregivers and their symptoms of anxiety, depression, and caregiver burden.

One question to be answered before intervention development and implementation is the suitability of such an approach in the target population. The use of internet banking services could give some indication of the availability of internet broadband. In Lithuania, the use of such services was found to approximate the European Union's average (Eurostat, 2021). In terms of internet speed, Lithuania is part of the top 20 European countries (Fair Internet Report, 2020), indicating high internet speed in the country. Due to high emigration numbers, it is not uncommon for individuals to communicate with family members and friends abroad using various internet devices and apps. This is also the case for the older residents, whose children and grandchildren might be residing abroad permanently. In terms of experience with smart devices, individuals aged 55 years or older were found to have lower media literacy and internet use than younger Lithuanian persons (Liubiniene \& Thunqvist, 2015). However, such findings are not surprising as research studies previously reported differences in the level of competence of using digital technologies between individuals in different age groups (e.g., Çoklar \& Tatli, 2021). All in all, it could be stated that the digitalization of the services in Lithuania is widely spread and accessible. Therefore, interventions offered online might not only be suitable but also appealing for the individuals. 


\subsection{Existing knowledge}

To the best of my knowledge, there are no previous research studies investigating ICBT suitability for informal caregivers in Lithuania. In general, internet intervention research in Lithuania is still scarce. Nevertheless, few internet intervention research studies have been conducted over the last years. One example is an internet-based modular program BADI that was developed for individuals suffering from adjustment disorder symptoms (Eimontas et al., 2018). The program consisted of four modules that incorporated CBT and mindfulness approaches. The program was unguided, meaning that individuals were able to choose the modules and engage with the program based on their own judgment and need. Following the use of the program, medium effect sizes were found for the reduction in adjustment disorder symptoms. It was overall concluded that such a selfguided program delivered over the internet has the potential in supporting individuals suffering from adjustment disorder symptoms.

Another recent example is a study by Dumarkaite et al. (2021) in which the effects of a mindfulness-based internet intervention were evaluated for supporting individuals experiencing posttraumatic and complex posttraumatic stress disorder symptoms. The intervention was a self-help program with the function of messaging support from a psychologist. The intervention consisted of eight modules consisting of psychoeducational materials and mindfulness exercises. Intervention's evaluation in the randomized controlled trial in the Lithuanian university student population indicated promising results, with participants found to overall indicate high satisfaction with the intervention. In terms of its effects, the intervention was successful in reducing the posttraumatic and complex posttraumatic stress disorder symptoms and promoting positive mental health.

In conclusion, the findings of these two research studies indicate that internet interventions have potential in the Lithuanian context. It also further encourages research into the suitability of internet interventions in different target groups. 


\section{AIMS OF THE THESIS}

The main aim of this thesis was to investigate if therapist supported Internetbased Cognitive Behavioural Therapy (ICBT) intervention can be an effective, acceptable, and feasible option to support Lithuanian informal caregivers. A second goal was to investigate the characteristics, burden, and support needs of the Lithuanian informal caregivers. To meet these goals, four research studies, each conducted within a different methodology, were performed. Each of the articles was dedicated to exploring a specific goal:

- Study I was a survey that investigated informal caregiver characteristics, knowledge, support needs, burden, and consequences of the COVID-19 pandemic on the caregiver and the care-receiver's well-being.

- Study II was a pilot randomized controlled trial that evaluated the effects of ICBT in reducing informal caregiver burden as well as symptoms of depression, anxiety, stress and increasing the quality of life.

-Study III was a qualitative study that evaluated the acceptability of ICBT via the analysis of the informal caregiver experiences.

-Study IV was a process evaluation study evaluating the intervention's suitability and potential for implementation based on the informal caregiver and stakeholder perspectives. 


\title{
7. Study I
}

\section{Lithuanian informal caregiver characteristics, burden and needs: a survey}

\begin{abstract}
Aim
The main aim of this study was to evaluate Lithuanian informal caregiver characteristics, support needs and burden. An additional aim was to evaluate the influence of COVID-19 on informal caregivers' and care-receivers' wellbeing.
\end{abstract}

\section{Methods}

\section{Design}

This study was a cross-sectional survey conducted online.

\section{Participants and recruitment}

The survey targeted Lithuanian informal caregivers or individuals with informal caregiver experience (for example, a relative of an informal caregiver). The main inclusion criteria were to be older than 18 years of age, be fluent in the Lithuanian language, have a phone or a compatible device, and have an internet connection for filling in the survey. The survey was advertised online via various Facebook groups and news outlets. Several relevant organisations, such as Huntington's disease association, were also contacted for dissemination purposes.

\section{Instrument}

The survey contained 62 multiple-choice questions. A total of 14 questions were dedicated to the demographic characteristics and 12 to the caregiver characteristics and care-related information in general. Then, there were seven questions requesting caregiving related knowledge and caregiver support needs. Lastly, there were five questions dedicated to the caregiver and care-receiver well-being and support during the COVID-19 pandemic and a 24-item long Caregiver Burden Inventory (CBI) (Novak \& Guest, 1989). The latter is a questionnaire evaluating informal caregiver perceived burden. CBI contains five subscales, each dedicated to a different aspect: Time Dependency, Development, Physical health, Emotional health, and Social Relationships. Each of the subscales has five questions with the exception of 
Physical health, which has four. The response options range from 0 ('Never') to 4 ('Nearly always'). The scores are summed up and range from 0 to 96 . The higher the score, the higher is the burden. The reliability of the CBI is high (Caserta et al., 1996).

\section{Procedure}

The survey was running between May and September of 2020. Interested individuals were requested to click on the survey's link. Upon opening, prospective participants were first presented with the aims of the study. Following this, participants were requested for their consent. Individuals who consented to take part in the survey were then taken to answer the survey's items.

Participants were not provided with monetary compensation for taking part in the study. Ethics approval was obtained from Vilnius University Psychology Research Ethics Committee, 08-07-2019 No.26.

\section{Analysis}

Analysis was conducted using IBM SPSS with free-text answers categorized were possible. The significance level was set at $\alpha=.05$. Descriptive statistics were used for summarizing participant characteristics, caregiving related items, support needs and COVID-19 responses. Independent samples $t$-tests and One-Way Analysis of Variance (ANOVA) were conducted for investigating the relationship between several demographic characteristics and the CBI scores. Multiple linear regression was performed with selected demographic characteristics entered as predictors, and the total CBI score entered as the dependent variable.

\section{Results}

\section{Demographic characteristics and caregiving background}

The survey was completed by 226 individuals. Most of the participants $(87.6 \%)$ and the care-receivers $(68.1 \%)$ were women. The mean age of the participants was 49 years $(S D=12.7)$ and of care-receivers - 71 years $(S D=23.31)$. Care-recipient was most often a parent to the informal caregiver $(57.1 \%)$. In turn, dementia was the most frequent reason for the care provision (22.6\%). Informal caregivers were found to be highly involved in care provision, with the majority providing care for seven days per week (79.6\%) for three to seven (32.7\%) or more than 12 hours (35.4\%) daily. 


\section{Knowledge and support needs}

Approximately half of the participants had no prior knowledge about the care provision $(55.3 \%)$ as well as symptom specifics of the care-receiver $(47.3 \%)$. Almost half (48.7\%) were not receiving any support, and the majority stated a need to receive more professional support (73.9\%). Psychological support was received by $2.2 \%$ of the participants.

\section{Burden}

Participants displayed high burden scores $(M=50.21, S D=15.63)$. Women were found to be significantly more burdened than men $(p=.011)$. Participants overall scored the highest on the Time Dependency subscale of the CBI measure $(M=16.15, S D=4.21)$. Following multiple linear regression analysis, gender of the caregiver $(p=.046)$, self-rated well-being $(p=.001)$, caregiving duration in months $(p=.006)$, and experience of the psychological health problems ( $p=.001$ ) were found to make a significant contribution explaining $27.3 \%$ of the variance in the overall CBI score.

\section{COVID-19}

According to the participant data, for the majority, COVID-19 did not make a significant impact on own (63.7\%) or care-receiver's (68.1\%) well-being.

\section{Discussion}

The results showed that Lithuanian informal caregivers were highly involved in care provision. Results also showed that caregivers experienced a high burden and a need for further professional support. Caregivers reported no changes in their own or the well-being of care-receivers due to the COVID19 pandemic.

There could be several ways in which informal caregiver well-being could be improved. Most importantly, current labour market measures could be improved to provide informal caregivers more flexibility. More options for respite and opportunities for professional support alongside accessible information sources should be offered.

Few limitations must be addressed. Most importantly, the sample might not be fully representative as more motivated informal caregivers or those with higher computer literacy could have taken part in the study. Secondly, only five questions addressed the pandemic's impact on the dyad's well-being and hence more detailed investigation should be conducted. 
Despite the limitations, this study enriched informal caregiver literature by providing knowledge concerning the Lithuanian informal caregiver characteristics, support needs and burden. Suggested recommendations should not only inform but also encourage further researchers and policymakers in adapting current policies and researching ways to support informal caregivers.

\section{Study II}

\section{Internet intervention for informal caregivers: a randomized controlled trial}

\section{Aim}

This study aimed to evaluate the effects of ICBT for reducing informal caregiver burden. Effects on symptoms of depression, anxiety, stress, and perceived quality of life, were also investigated.

\section{Methods}

\section{Design}

The study was a two-armed pilot randomized controlled trial (RCT). Participants were randomly allocated to either an intervention group or a waitlist control group. The only difference between the groups was that the participants in the control group had to wait for eight weeks before receiving access to the intervention.

\section{Participant inclusion and recruitment}

Participant recruitment took place online via advertisements placed on media, radio, and television. The main inclusion criteria were to be older than 18 years, to score 24 or more points on CBI (Novak \& Guest, 1989), have access to the computer, phone or a compatible device and internet connection and be fluent in the Lithuanian language. Individuals who experienced severe physical or psychiatric symptoms or interpersonal violence were not included. Also, participants providing care for individuals with a life expectancy of six or fewer months were excluded. 


\section{Instruments}

The main outcome measure was the CBI (Novak \& Guest, 1989) which is a questionnaire consisting of 24 items spread over five distinct categories. A full description of the CBI is provided in Study I. The secondary measures included were the nine-item Patient Health Questionnaire-9 (PHQ-9) (Kroenke et al., 2001) measuring depressive symptoms, the seven-item Generalized Anxiety Disorder-7 (GAD-7) (Spitzer et al., 2006) questionnaire measuring anxiety symptoms, the 14-item Perceived Stress Scale-14 (PSS14) (Cohen et al., 1983) measuring stress symptoms and two questionnaires measuring the quality of life - the 12-item long Brunnsviken Brief Quality of Life Scale (BBQ) (Lindner et al., 2016) and 5-item long The World Health Organization-Five Well-Being Index (WHO-5) (Topp et al., 2015). Lastly, two additional measures were used for the baseline assessment: The Life Events Checklist (LEC) (Weathers et al., 2013) and The Alcohol Use Disorders Identification Test (AUDIT) (Saunders et al., 1993). LEC was used for assessing the possibility of previous traumatic experiences, while AUDIT was used for assessing the alcohol consumption of prospective participants.

\section{Intervention}

The intervention was an eight-week-long therapist supported self-help ICBT program. A secure online platform Iterapi (Vlaescu et al., 2016), was used for delivering the intervention. The intervention's content was selected from previous ICBT trials conducted at Linköping University (e.g., Andersson, 2015; Andersson et al., 2006; Andersson et al., 2012). Selected content was translated into the Lithuanian language. Then, to assure its cultural appropriateness, the content was revised with the help of native Lithuanian clinical psychologists engaged in research. The intervention consisted of eight modules, each dedicated to a different theme. The themes were: Introduction, Thoughts, Stress and relaxation, Problem solving, Communication, Anxiety, Behavioural activation, and Maintenance. Each module consisted of psychoeducational materials, examples and one or a few exercises. The list of the modules together with respective aims and exercises are provided in Table 1. The intervention was to be used independently, but at the same time, participants were able to contact the therapist, who would answer questions and provide feedback for conducted exercises. The communication between the informal caregiver and the therapist took place over messaging via the intervention's platform. The therapists were three clinical psychologists engaged in research and three Master level Clinical Psychology students. 
Table 1

List of intervention's modules, respective aims, and exercises.

\begin{tabular}{|c|c|c|c|}
\hline & Module & Aim & Exercises \\
\hline 1 & Introduction & $\begin{array}{l}\text { To introduce the } \\
\text { intervention and the } \\
\text { principles of the CBT. }\end{array}$ & $\begin{array}{l}\text { - Reflecting on short- } \\
\text { term and long-term } \\
\text { consequences. } \\
\text { - Formulating personal } \\
\text { goals for the treatment. }\end{array}$ \\
\hline 2 & Thoughts & $\begin{array}{l}\text { To the introduce } \\
\text { thought-emotion- } \\
\text { behaviour cycle with } \\
\text { the focus on the } \\
\text { thought aspect. }\end{array}$ & $\begin{array}{l}\text { - Reflecting on thinking } \\
\text { errors. } \\
\text { - Practising thought } \\
\text { diary. }\end{array}$ \\
\hline 3 & $\begin{array}{l}\text { Stress and } \\
\text { relaxation }\end{array}$ & $\begin{array}{l}\text { To introduce stress and } \\
\text { its effects on the } \\
\text { human body and ways } \\
\text { to deal with it. }\end{array}$ & $\begin{array}{l}\text { - Reflecting on stress- } \\
\text { induced effects. } \\
\text { - Reflecting on how to } \\
\text { reduce these effects. } \\
\text { - Planning what } \\
\text { activities could help to } \\
\text { reduce stress. } \\
\text { - Practising relaxation } \\
\text { methods. }\end{array}$ \\
\hline 4 & $\begin{array}{l}\text { Problem } \\
\text { solving }\end{array}$ & $\begin{array}{l}\text { To introduce different } \\
\text { problem solving } \\
\text { strategies and practise } \\
\text { applying them. }\end{array}$ & $\begin{array}{l}\text { - Reflecting on own } \\
\text { problem solving abilities } \\
\text { and difficulties. } \\
\text { - Reflecting on own } \\
\text { problem solving style } \\
\text { and orientation. } \\
\text { - Practising six-step } \\
\text { problem solving } \\
\text { method. }\end{array}$ \\
\hline 5 & $\begin{array}{l}\text { Communicati } \\
\text { on }\end{array}$ & $\begin{array}{l}\text { To discuss possible } \\
\text { changes in } \\
\text { communication after } \\
\text { starting to provide care } \\
\text { and how to manage } \\
\text { them. }\end{array}$ & $\begin{array}{l}\text { - Reflecting on the } \\
\text { changes in } \\
\text { communication since } \\
\text { providing care. } \\
\text { - Practising one of the } \\
\text { three exercises: } \\
\text { a. six-step problem } \\
\text { solving method, } \\
\text { b. perspective change } \\
\text { method, }\end{array}$ \\
\hline
\end{tabular}




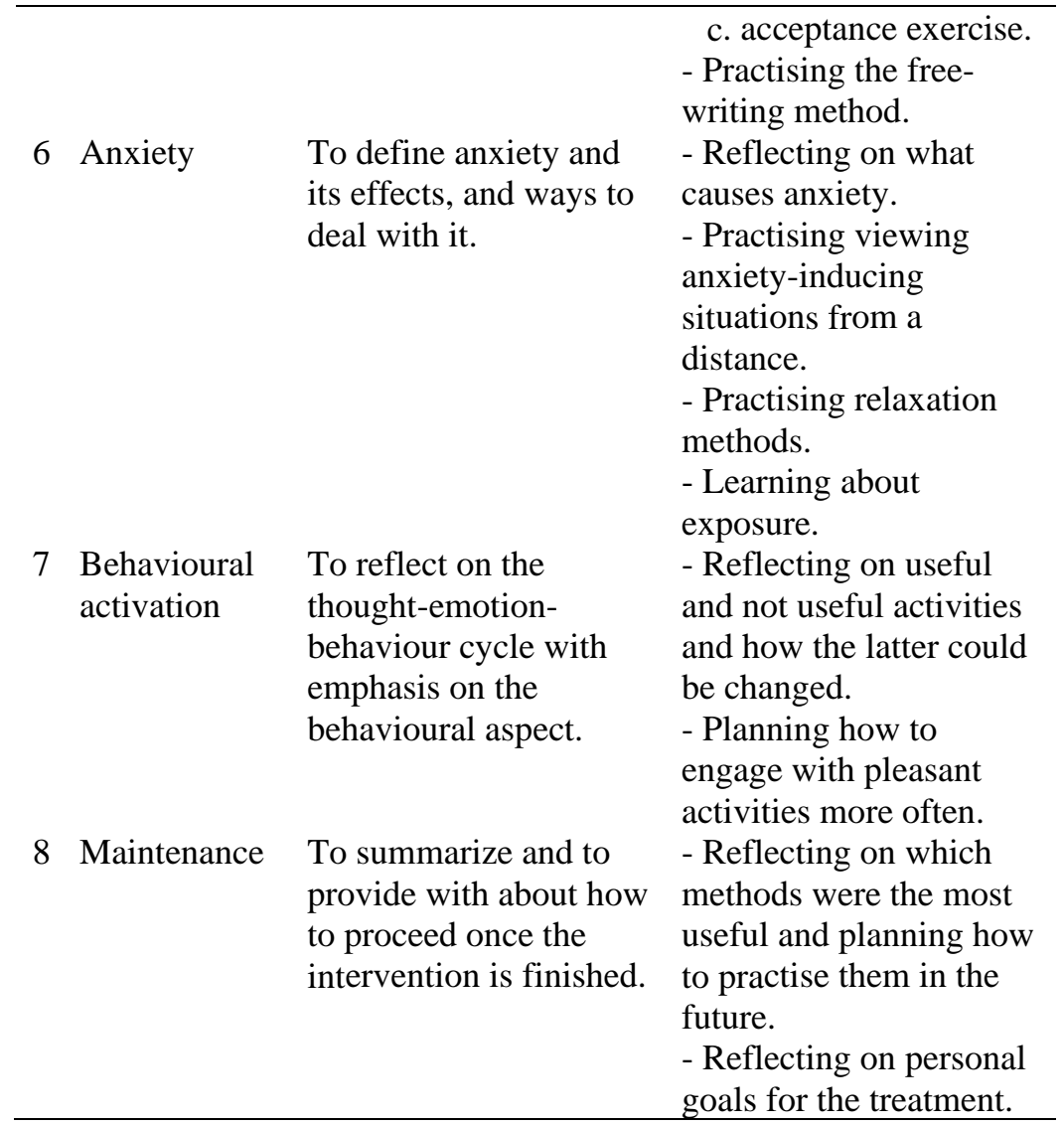

\section{Procedure}

When opening the study website, individuals were first provided with information about the study. Interested informal caregivers were then able to register by first providing informed consent and second, filling in the questionnaires. After this, prospective participants were invited for a short phone interview. After the interview, a final decision about inclusion or exclusion in the study was made. Included participants were then randomized into intervention and wait-list control groups using a website for the generation of random numbers (www.random.org). Participants in the intervention group started using the intervention shortly after the randomization, while the wait-list control group participants after the eightweek-long waiting period. 


\section{Analysis}

Data analysis was performed using IBM SPSS. Data were treated according to the intention-to-treat (ITT) principle that states that all randomized participant data will be analysed despite their engagement with the intervention (Gupta, 2011). In addition, a multiple imputation procedure was used, considering that data were missing at random (MAR) (Jakobsen et al., 2017). The main analysis consisted of descriptive statistics, calculation of between and within-group effect sizes (Cohen's $d$ ) and analysis of covariance (ANCOVA) for evaluating the effects of the intervention at the posttreatment. In addition, significance in the change of the caregiver burden was evaluated by calculating the Reliable Change Index (RCI) according to the Jacobson and Truax method (Jacobson \& Truax, 1992). The significance level was set at $\alpha=.05$.

\section{Results}

A total of 86 individuals expressed an interest in taking part in the study. It was possible to include 63 participants, out of which 31 were randomized to the intervention and 32 to the wait-list control group. Most of the informal caregivers $(90 \%)$ and their care-receivers $(70 \%)$ were female. Most often care-receiver was a parent to the informal caregiver (70\%). The majority of the informal caregivers were highly involved in care provision, providing care for 5-7 days per week $(86 \%)$ for either 3 to 7 hours $(38 \%)$ or more than 12 hours $(37 \%)$ per day. The mean burden score as measured by the CBI was 53.92 points $(S D=12.66)$ and indicated participants to experience a high burden.

Post-treatment measures were collected from 25 participants in the intervention and 29 in the wait-list control group, approximating to a dropout rate of $19 \%$. Regarding main effects, between-group effect sizes indicated a moderate reduction in caregiver burden $(d=-0.70)$ as well as depression $(d=$ -0.69) and anxiety ( $d=-0.74)$ symptoms for participants in the intervention group. Also, high reduction in stress symptoms $(d=-1.06)$ and high effects sizes for increase in the quality of life $(d=0.8$ and 0.85$)$. The ANCOVA's results revealed significant group effects on post-treatment scores when controlled for pre-treatment scores for all measures. Significantly more participants in the intervention group, as opposed to the control group participants, achieved positive RCI for CBI $(p<.001)$. However, only two participants in the intervention group $(6.5 \%)$ achieved clinically significant change for their caregiver burden scores as measured by the CBI. 


\section{Discussion}

The results of this study indicated that self-help therapist support ICBT intervention can be at least moderately effective in reducing informal caregiver burden as well as depressive and anxiety symptoms and highly effective in reducing stress and improving the perceived quality of life. These findings are in line with previous research studies outlining internet intervention potential in supporting informal caregivers (Spencer et al., 2019).

Certain limitations should be kept in mind when interpreting these findings. Firstly, the study did not control for the external help informal caregivers were receiving. Also, the sample was self-referred. In addition, these findings are based on a small pilot sample.

Despite the limitations, the study was one of the few to investigate ICBT intervention's effectiveness for informal caregivers. More so, it was the first study to evaluate ICBT effects for Lithuanian informal caregivers. Since the participants were providing care for individuals with various health complaints, it also suggests that such intervention can be applicable for informal caregivers supporting individuals with a range of needs.

\section{Study III}

\section{Internet intervention for informal caregivers: a qualitative study}

\section{Aim}

The aim of Study III was to evaluate the experiences of Lithuanian informal caregivers using the ICBT intervention to assess its acceptability.

\section{Methods}

\section{Design}

A qualitative design was employed with a selected sample. It was conducted as a follow-up to Study II, which focused on evaluating the intervention's effects. 


\section{Participants and recruitment}

Participants in both groups were approached for taking part in the study. Participants in the intervention group were approached two months after completing the intervention, while in the control group - straight after. A total of 23 participants agreed to take part in the phone interviews, 12 from the wait-list control and 11 from the intervention group. All participants except one were female (96\%). The average age of the participants was 54 years $(S D=7.51)$. The majority were providing care for their father or mother $(74 \%)$, who was an average of 75 years old $(S D=17.81)$. Participants were providing care for individuals experiencing various health problems. Dementia and frailty due to the old were the two most common ones. Characteristics of the sample in this study did not significantly differ from the full sample.

\section{Materials and procedure}

A semi-structured interview guide was prepared for the phone interviews with the help of two Master of Clinical Psychology students familiar with the intervention and the previous clinical trial. The guide contained several openended questions and suggestions for the probes. All interviews were conducted by the author of this thesis.

Participants were contacted by either phone or email and requested about taking part in the phone interviews. In addition to describing the aims of the study, participants were also explained that the interviews would be recorded, and that the data would be anonymized. Phone interviews ranged between 8 and 32 minutes, with an average interview lasting 16 minutes. Recordings were transcribed. The study was approved by the Vilnius University Psychology Research Ethics Committee, documented as 08-07-2019 No.26 and consent was obtained from all participants.

\section{Analysis}

Data were analysed using the inductive reflexive Thematic analysis approach (Braun \& Clarke, 2020) conducted within the essentialist/realist paradigm. Several steps were followed for conducting the analysis (Braun \& Clarke, 2006). Firstly, transcriptions were read several times. All transcripts were then coded systematically, labelling segments of text with short phrases. Five candidate themes and 16 sub-themes were then formed by collating the codes together. These themes were then compared to refine them. During the refinement process, it became evident that some of the themes must be merged together to represent the data in a meaningful and coherent manner. Consequently, five themes were reduced to four main themes with a total of 
10 sub-themes. The analysis process was performed by the author and another female researcher fluent in the Lithuanian language and under the continuous supervision of three researchers experienced in qualitative methods.

\section{Results}

The main themes and the sub-themes are presented in Table 2. The first and second themes represent informal caregiver direct experiences of using the intervention. In turn, the remaining two themes represent certain aspects concerning the personal and situational circumstances of the caregivers that should be considered in further intervention's development.

Table 2

Resulting themes and sub-themes following the interviews with informal caregivers.

\begin{tabular}{|c|c|}
\hline $\begin{array}{c}\text { I A program as a means of } \\
\text { change }\end{array}$ & II Suggestions for the program \\
\hline $\begin{array}{l}\text { Convenience and applicability of } \\
\text { the format and materials }\end{array}$ & Including live support \\
\hline Ability to focus on own needs & Tailoring materials and format \\
\hline Opportunity for communication & $\begin{array}{l}\text { Providing with more time and } \\
\text { resources }\end{array}$ \\
\hline $\begin{array}{l}\text { III Driving personal and } \\
\text { situational forces }\end{array}$ & IV Hindering situational factors \\
\hline $\begin{array}{l}\text { Developing acceptance and } \\
\text { adjustment over time }\end{array}$ & $\begin{array}{l}\text { Deterioration and unpredictability } \\
\text { of the care-receivers health }\end{array}$ \\
\hline $\begin{array}{l}\text { Being proactive and/or receiving } \\
\text { support }\end{array}$ & $\begin{array}{l}\text { Lacking external support and } \\
\text { opportunities for respite }\end{array}$ \\
\hline
\end{tabular}

The first theme, A program as a means of change, informed about three aspects, which informal caregivers found the most useful about the ICBT. To start with, participants appreciated the selection of the topics and the fact that it was possible to use the intervention in their own preferred time. Secondly, informal caregivers appreciated that the intervention encouraged them to focus on their own needs. Lastly, informal caregivers found it beneficial that the intervention allowed them an opportunity to share their own experiences and stories. 
As opposed to the first theme, the second theme, Suggestions for the program, informed about three aspects that could be further developed to maximize the benefits of the intervention. The first concerned the inclusion of live support options, such as a phone call to the therapist, in addition to the implemented messaging function. The second one informed that the online transdiagnostic format was not equally useful for all informal caregivers. That is, some caregivers were found to prefer a more personalized approach. Lastly, the third sub-theme outlined that some informal caregivers experienced the need to receive more time for using the intervention. In addition, some informal caregivers were found to experience the need for receiving more information than the intervention already provided.

The third and the fourth themes introduced certain personal and situational factors affecting informal caregiver well-being and hence, their support needs. Two aspects within the third theme, Driving personal and situational factors, were outlined as maintaining informal caregiver psychological health. These were developing acceptance and adjustment over time, receiving professional support or support from social circles, and being proactive in trying to maintain own well-being. As opposed to this, theme four, Hindering situational factors, outlined the lack of respite and support to impact informal caregiver psychological well-being negatively. In addition, worsening and unpredictability of the care-receivers health were indicated as additional hindering factors to informal caregiver well-being.

\section{Discussion}

The main aim of this study was to evaluate the acceptability of ICBT for informal caregivers. The findings suggest that caregivers, in general, found the intervention to be acceptable. More specifically, they found the content to be suitable. In addition, informal caregivers appreciated that the intervention provided them with an opportunity to focus on their own needs. Also, that it allowed them to share their own experiences with the therapist. Such findings are in line with other research studies indicating internet intervention potential for informal caregivers (Sherifali et al., 2018). At the same time and similar to other research studies (Rozental et al., 2015), the intervention was not found to be equally acceptable by all participants. Some of the participants were found to experience the need for a live support option, the need for more materials and an opportunity for personalization.

There are several limitations that should be kept in mind when interpreting these findings. Possibly one of the most important ones is the interviewer's 
involvement in the research trial. For eight of the interviewed participants, I have served as a therapist during the effectiveness trial. This could have had a negative impact on participants' ability to express their experiences with the intervention. At the same time, participant information was anonymous, and no physical contact was established during the trial, all of which should have minimised such risks.

In summary, to the best of my knowledge, this study was the first to evaluate Lithuanian informal caregiver experiences of using transdiagnostic, therapist supported ICBT. Based on the results, it could be concluded that the intervention was mostly deemed to be acceptable by the caregivers. In addition, the results outlined certain possible areas for further interventions development, such as considering the inclusion of the life support options and personalizing the content.

\section{Study IV}

\section{Internet intervention for informal caregivers: a process evaluation}

\section{Aim}

The aim of study IV was to conduct a process evaluation of the ICBT for Lithuanian informal caregivers in follow-up to studies II and III.

\section{Methods}

\section{Design}

The study was conducted following Study II and Study III and was designed as a process evaluation consisting of two parts. The first part (study 1) was based on the previously unused informal caregiver data obtained during Study II. The second part (study 2) was a focus group discussion with eight stakeholders. Results of both studies are integrated into the discussion.

\section{Intervention development}

The development of the intervention compromised three stages: 1) concept development, 2) content selection, and 3) revision. In all three stages, a team of psychologists engaged in research, including Lithuanian nationals, were involved. A description of the content of the intervention was provided in Study II. 


\section{Participants and recruitment}

The participants in the first part were informal caregivers who took part in Study II. Women participants compromised the majority of that sample (90\%). The mean age of the participants was 52 years $(S D=8.4)$. Most of the care-receivers were also female $(70 \%)$, and the mean age was 71 years $(S D=21.1)$.

In the second part, a convenience sample of eight stakeholders was recruited by contacting several Lithuanian caregiver organizations, as well as a list of existing contacts. All stakeholders were female. The average age of stakeholders was 47 years $(S D=7.66)$. All participants had informal caregiving experience either through their work or their own experiences of providing care.

\section{Materials}

Part one data consisted of four multiple-choice module evaluation questions and an open box answer, as well as an additional open box answer for sharing experiences or thoughts regarding the previous module. The questions were: 'How can your rate your current well-being?'; 'Approximately what percentage of all the given information did you read?'; 'How do you overall rate this session?'; and 'How much time did you spend reading the materials and conducting the exercises?'. The questions were already embedded in the intervention for the effectiveness trial. Only three out of the multiple-choice questions were included since the remaining ones were requesting about participants' well-being.

In the second part (study 2 in the paper), a discussion guide was prepared for structuring the discussion. The focus was on three main aspects: 1) publicly available information on the main page of the intervention, 2) the intervention's content and format, and 3) therapist support. In addition, a PowerPoint presentation introducing the intervention was available for participants who wanted to familiarize themselves with the program before the discussion.

\section{Procedure}

Informal caregivers were using the ICBT intervention for eight weeks between October 2019 and March 2020. Answering module evaluation questions was not mandatory, and participants were able to do it of free will. Ethics approval for the effectiveness study was obtained from the Vilnius 
University Psychology Research Ethics Committee documented as 08-072019 No.26.

The focus group discussion took place online via Zoom in November 2020. Prior to the discussion, all participants had to familiarize themselves with the study aims and provide their consent. At the start of the discussion, participants were once again requested to provide consent to participate and to record the session. I have chaired the discussion, and a Master level of Clinical psychology student took notes. Shortly after the discussion, participants were provided with the discussion's summary.

\section{Analysis}

In the first part, descriptive statistics were performed for summarizing quantitative answers using the IBM SPSS Statistics program. The qualitative answers were first coded and then integrated into categories (Blair, 2015).

In the second part of the study, reflexive Thematic Analysis (Braun \& Clarke, 2020) was used for interpreting the data within an essentialist/realist approach. Six steps were followed for conducting the analysis (Braun \& Clarke, 2006), starting from familiarizing with the data and then moving to data coding, searching for, and then forming the themes, then refining and naming the themes to produce the report. Data analysis was performed by me with the help of the Master level Clinical psychology student fluent in the Lithuanian language as well as with the help of the research supervisors to assure the reliability of the process.

\section{Results}

Quantitative analysis of the participant responses in the first part revealed that most of the participants $(35.6 \%-60 \%)$ spent between 30 minutes to 1 hour engaging with a single module and that majority of participants $(77.1 \%$ to $93.5 \%$ ) read all the information for the given module. In addition, most of the modules were rated as good (24.3\%-46.2\%) or very good (33.3\%-57.7\%). Consequently, following qualitative analysis, participant comments were divided into three main categories, expressing participant 1)satisfaction, 2)doubts, and 3)lack of satisfaction with the intervention: Content/format positive (72.2\%), Content/format hesitant (20.4\%) and Content/format negative $(7.4 \%)$ respectively. Comments in the Content/format positive category were further divided into five categories, outlining which aspects of the program were specified to be appreciated by the participants: learning about thoughts $(31.5 \%)$, overall applicability $(23.6 \%)$, being able to relax $(13.4 \%)$, dedicating time for own needs $(12.6 \%)$ and other $(18.9 \%)$. The latter 
sub-category 'other' included the appreciation of the problem-solving information $(5.5 \%$ out of $18.9 \%)$, therapist communication $(7.9 \%$ out of $18.9 \%)$ or communication-related knowledge $(5.5 \%$ out of $18.9 \%)$

Reflexive Thematic Analysis in the second part of the study resulted in one main theme and four sub-themes (Table 3). The main theme, together with the sub-themes, informed that the intervention, to the most extent, was deemed to be beneficial for the caregivers. At the same time, data analysis outlined that some of its aspects could be developed further. To start with, better provision of the instructions should be considered. In addition, certain personalization options should be made available, such as an opportunity to queue the modules according to individual preferences. Lastly, a list of useful resources should be provided so that caregivers would have additional support in maintaining their well-being after the intervention is finished.

Table 3

Main theme and sub-themes following stakeholder discussion.

\begin{tabular}{cl}
\hline Main theme & \multicolumn{1}{c}{ Sub-themes } \\
\hline & $\begin{array}{l}\text { Feasible and needed } \\
\text { Need to clarify instructions and manage } \\
\text { expectations } \\
\text { ICBT intervention's } \\
\text { potential and }\end{array}$ \\
& $\begin{array}{l}\text { Need to provide with guidance after the } \\
\text { intervention has ended } \\
\text { Similar challenges, but need of flexibility }\end{array}$ \\
\hline
\end{tabular}

\section{Discussion}

Two studies were conducted as part of this process evaluation. The first part was based on the informal caregiver data, while the second part was based on data from the stakeholders. The findings of both studies could be summarized by stating that the intervention was found to be suitable for informal caregivers. The most valued aspects of the intervention outlined were the intervention's applicability and the fact that it encouraged informal caregivers to spend the time for their own needs. The ability to learn about own thoughts and communicate with the therapist was also highly valued. At the same time, data made it evident that the intervention was not equally useful for all informal caregivers. Therefore, several ideas concerning further ICBT's 
development were outlined. These included clarifying the instructions, providing more guidance, and including options for personalization.

There are limitations to be discussed. Firstly, a process evaluation study was conducted following a pilot RCT study and a qualitative study for evaluating the effectiveness and acceptability of the intervention. On the one hand, it could be argued that process evaluation should have been conducted first, following the development of the intervention. On the other hand, the intervention was based on already existing and evaluated materials used in other ICBT research trials for adult populations. Also, the Lithuanian research team was involved in evaluating the quality of the materials and their suitability for the target population. Another limitation is the relatively small sample sizes of the informal caregivers and stakeholders that could overall limit the generalizability of the findings.

Overall, findings indicate that the intervention has the potential to benefit informal caregivers. Future research studies should focus on implementing suggestions outlined by the informal caregivers and stakeholders. Following this, further research trials are warranted for evaluating its feasibility and potential for implementation. 


\section{GENERAL DISCUSSION}

The main goal of this thesis was to evaluate the suitability of ICBT for Lithuanian informal caregivers. In addition, the secondary aim concerned an investigation of Lithuanian informal caregiver characteristics. To fulfil these aims, four research studies were conducted. Study I investigated informal caregiver characteristics, while Studies II-IV evaluated the intervention. The results provided initial evidence in favour of ICBT and its suitability. In the following paragraphs, I will first discuss findings concerning the secondary aim, the informal caregiver characteristics. After this, I will discuss the findings concerning the suitability of ICBT for Lithuanian informal caregivers.

\subsection{Informal caregiver characteristics}

Study I and Study II have resulted in a list of variables indicating Lithuanian informal caregiver characteristics. To start with, most of the participants in both studies were female in their early fifties providing care for most days of the week for several years. Most informal caregivers in both studies were also found to have a university degree and be married. The care-receiver was most often a mother to the caregiver. In addition, in both studies, informal caregivers could be identified as intensive caregivers providing care for more than 11 hours per week (Verbakel et al., 2017).

How do Lithuanian informal caregiver characteristics relate to the characteristics of the caregivers outlined in other European countries? In terms of average informal caregiver age and gender, the findings are in line with previous research findings indicating caregiving to be most prevalent among women in their fifties (Tur-Sinai et al., 2020; Verbakel et al., 2017). Informal caregiving was also previously found to be more prevalent among individuals with higher education (Tur-Sinai et al., 2020) which is in line with our findings. The finding that a majority of the respondents in both studies were intensive caregivers is more surprising as previous research findings estimated intensive caregivers to approximate less than 10 percent of the caregiver population (Verbakel et al., 2017).

Another characteristic concern the caregiver burden. In both studies, informal caregivers scored approximately 50 points on the CBI measure (Novak \& Guest, 1989), for which scores of 24 or above suggest a need for respite, and scores above 36 a risk for burnout. Based on this, the samples in our studies experienced a high caregiver burden. Indeed, Study I showed that informal caregivers experienced a lack of knowledge prior to caregiving 
and a need for more professional support as almost half of the respondents were not receiving any support at the time of the survey. These findings are further supported in Study III, in which caregivers expressed a need for more information and resources to support them in their role as caregivers.

Some research findings in other countries have also previously identified informal caregivers to experience high levels of burden. One example is a study in which Australian informal caregivers for people with dementia were found to experience high and persistent (extending to 12 months) burden (Brodaty et al., 2014). At the same time, variability in the caregiver burden in different European countries was previously identified (Alvira et al., 2015). A difference in the experience of burden could at least be partially explained by cultural differences and expectations towards care provision as well as differences in the healthcare systems. In the case of Lithuania, the lack of knowledge and the high involvement in the care provision could at least to some extent explain the high caregiver burden scores reported by participants in Studies I and II. High caregiver burden could also occur as a consequence of a lack of integration between the healthcare and social services in Lithuania as well as due to the limited options for respite and limited availability of formal support options for informal caregivers (Žalimienè et al., 2020).

Overall, Study I (and partially Study II) findings show that informal caregivers experience a high strain and unmet needs. Even though Study I was conducted following the evaluation of the ICBT, it provides evidence for the development and implementation of the support services for the informal caregivers. Nevertheless, it must be emphasized that there are limitations. In addition, it should not be concluded that all Lithuanian informal caregivers suffer from highly negative caregiving outcomes. Both, Study I and II were focused on investigating the needs, burden, and the way of reducing it with the help of the ICBT intervention. Therefore, both studies were focused on the negative caregiving outcomes that could add to the image of care provision being overly a difficult experience. I will further reflect upon this aspect in the limitations section.

\subsection{ICBT for informal caregivers: overall findings}

Studies II-IV focused on evaluating the effects, acceptability, and overall suitability of the ICBT for Lithuanian informal caregivers. Findings could be separated into two broad categories: 1) benefits and 2) further developments of the ICBT. 


\subsubsection{ICBT benefits}

The ability to focus on own needs was outlined as one of the more beneficial aspects of the intervention (Study III). That is, the intervention was perceived as a 1) tool encouraging self-care and, also, 2) as an opportunity for spending some time for oneself, away from the demands of daily life. In relation, the Behavioural Activation module of the intervention was outlined as the most useful module (Study II). This module specifically focused on time scheduling and the incorporation of pleasant activities for the caregiver. It is evident that informal caregiving can be demanding psychologically and physically. It can also result in activity restriction (Revenson et al., 2016) that might limit individuals' time and resources. In addition, it is common that informal caregivers experience difficulty managing their caregiving tasks with other daily demands and negative feelings, such as guilt (Lopez Hartmann et al., 2016) that stems from it. Since a majority of informal caregivers in Study II were intensive caregivers, the information provided in the Behavioural Activation model could have been effective in helping the caregivers to organize their tasks and hence reduce the negative affect. In addition, incorporation of such activities in daily routine could have helped caregivers experience more positive affect and reduce the negative caregiving outcomes. The latter could also be evident by medium to high effect sizes for the reduction in the burden, depression, anxiety, and stress scores and increase in the quality of life for the caregivers in the intervention group.

In terms of the content and in addition to the Behavioural Activation, participants in Study IV valued information about thoughts and thinking processes. Identification of the thought patterns and modification of the negative automatic thoughts is one of the key CBT aspects as cognitive processing is given a central role in most cognitive-behavioural models (Wright et al., 2017). Forand et al. (2018) found that the early improvement in cognitive skills, and more specifically, identification and modification of the negative emotions, can mediate the reduction in the depressive symptoms following ICBT (Forand et al., 2018). It could therefore be suggested that this aspect of the intervention was perceived positively due to its applicability and benefits for the participants. In addition, Study IV results indicated that informal caregivers overall experienced the content as applicable and relevant. These findings are also evident from the Study II results, in which almost half of the participants indicated all intervention's modules to be useful and Study III, in which participants indicated the themes of the intervention were relevant. 
Communication with the therapist is an additional aspect that should be reflected upon. Since Study II-IV results indicated participants to have different experiences, it could be listed under both the benefits and the needs for further developments. The latter will be reflected upon in the following section. In turn, participants who valued the existing communication function indicated that it provided them with an opportunity to open up, share and receive feedback from the therapists. Study III findings indicated that such function was of relevance in cases where caregivers' contacts were limited, or caregivers did not feel confident in discussing the topics with anyone else. This could be further evidenced by the findings of Study II, in which $44 \%(11 / 25)$ of participants indicated therapist support to be useful and $28 \%(7 / 25)$ as very useful. Benefits of therapist support have been recognised previously (e.g., Baumeister et al., 2014). Based on the study findings, such function was also beneficial to at least a part of the informal caregivers using the ICBT intervention.

\subsubsection{Further development of intervention}

Arguably some of the most important findings in the thesis concern the further development of ICBT. The overarching finding is that individual differences matter and should be accounted for in providing informal caregivers with support. More specifically, regarding the content and the communication function with the therapist. In addition, several less essential aspects should be considered, such as improving the intervention's usability information provided on the website.

\subsubsection{Personalizing the format}

The need for personalized options is of no surprise. Apart from their own individual differences, informal caregivers are faced with different circumstances. As participants in Studies III and IV reported, personal, and situational factors matter in how one adapts to the changed situation as a consequence of the care provision. There is also an aspect of time: someone at the start of the care provision might experience more stress than someone who has already adjusted to the new demands (Bookwala, 2009; Revenson et al., 2016). Also, it can be the other way round that the caregiving might become more demanding with the time passing by, as suggested by the caregiver wear and tear hypothesis (Townsend et al., 1989). Lastly, the care-receivers condition also plays a role. To name an example, care provision for an individual with dementia might become more demanding as the disease progresses. Therefore, as a starting point, intervention should offer informal caregivers an opportunity to select the modules based on their needs. This could be done by the assigned therapist based on the initial 
individual's assessment. In such a way, it would be possible to keep the transdiagnostic format of the intervention (applicable for a broad range of individuals) and at the same time offer an opportunity for individualization of the program based on caregivers' circumstances. In addition, I propose that based on individual preferences, some individuals could be offered scheduled phone check-ups to account for the need for the live support option. Such a strategy is not uncommon and has previously been applied in other trials (e.g., Pihlaja et al., 2020). This, however, should be further evaluated in the light of existing resources and further sustainability of the intervention.

\subsubsection{Content related changes}

To meet the goal of personalization, certain content-related changes could also be implemented. First, as outlined in Study III, some informal caregivers would benefit from practical information in relation to caregiving. Such need has also been outlined in previous research studies evidencing caregivers to experience the lack of and need for such support (Lund et al., 2015). Hence, an additional model focused on practical caregiving information could be added. Such a section could also include references to some additional resources covering specific disease-related information. Second, additional information should be included, accounting for changes in the caregiving across time. For example, adapting to the changes in the caregiving demands caused by the progression of the carereceivers disease. Duggleby et al. (2017) have designed an intervention based on the adaptation of the transition theory (Meleis, 2010). Their intervention was focused on increasing the self-efficacy, hope and healthrelated quality of life for the informal caregivers transitioning through various stages of their caregiving journey. The intervention included multiple components, some of which could also be accounted for and incorporated in ICBT. More specifically, information about what transitions informal caregivers might expect and how to understand and build upon their own inner strengths to successfully adapt to them (Duggleby et al., 2017). Third, the findings in Study II showed that throughout the intervention, at least three individuals had lost their care-receiver. Therefore, an additional module addressing bereavement should be considered. Lastly, the findings of Studies III and IV outlined the need for the continuation of the support. Therefore, an additional module containing references to various support channels should be included.

\subsubsection{General improvements}

In Study IV, stakeholders outlined that the intervention's use instructions could be made clearer. More specifically, a suggestion was made to provide 
indications about how to use the intervention and how much time participants might need to dedicate to using it. Such information could potentially be added on the publicly available page as well as in the very first module of the intervention. In addition, stakeholders suggested the provision of shortcuts that would allow participants to smooth transitions between previous materials or most recent exercises. It should be mentioned that since a great proportion of the informal caregivers in Study II indicated that the intervention was either easy $13 / 25(52 \%)$ or very easy to use $(6 / 25$, $24 \%)$, the suggested changes could be viewed as an advisory.

\subsection{LIMITATIONS}

The findings described in this thesis should be viewed in light of the limitations. I will discuss them point-by-point below, starting from the development of the intervention to the outcome assessment and the possible influence of the COVID-19 pandemic.

\subsubsection{ICBT development}

In Study II, the ICBT program for the informal caregivers was put together by selecting modules from existing materials as well as translating and adapting them to fit the target population of Lithuanian informal caregivers. Cultural adaptation requires the intervention to be modified to fit specific cultural values and the meaning assigned to them. Our cultural adaptation was based on the knowledge of the Lithuanian research team members. The research team was involved in the selection of the content and its translations which was also checked several times before the final version of the program was approved. Despite that, one limitation stems from the fact that we did not actively engage stakeholders in the development process. Involvement of the stakeholders would have been preferable and could have enriched the intervention's adaptation process. Nevertheless, due to the pilot nature of the study, a decision was made to rely on the experience of the research team and, if needed, further adapt the intervention following its initial evaluation.

\subsubsection{Sample representativeness}

Studies III and IV were based on the sub-samples of participants from Study II (with the addition of stakeholders in Study IV) and included a total of 63 informal caregivers. In turn, Study I was based on a separate sample of 226 participants. Characteristics of the participants in both samples were very similar in terms of age (mostly mid-years), gender (majority women) and basic caregiving characteristics (such as time spent on care provision). It 
could be suggested that the similarity between the samples provides some grounds for assuming their representatives. However, the fact that women compromised the majority of both samples also encourages further questioning. That is, it could be suggested that the invitation to take part in the studies was more appealing for women informal caregivers. Also, since the invitations were mostly disseminated online, they were more accessible for informal caregivers with more frequent use of the internet. At the same time, women are found to be caregivers more often than men (Tur-Sinai et al., 2020). Also, in terms of age, the mean age of caregivers in our samples closely approximates the caregiver age reported in other studies (Verbakel et al., 2017). Therefore, even though we have some confidence about the samples being at least partially representative of the informal caregiver characteristics in Lithuania, further research should be conducted to include larger participant samples recruited via various channels.

The fact that the qualitative and process evaluation findings were based on the sub-sample of the participants in Study II could be viewed as another limitation. More specifically, the qualitative interviews in Study III and the intervention evaluations in Study IV. It could be argued that participants who voluntarily chose to take part in the interview or fill in the evaluations were either more positive or alternatively more negative about the intervention. Therefore, further qualitative interviews and program evaluation questionnaires could be obtained from larger samples, assuring that participants with a range of experiences are included.

Lastly, it must be outlined that Study II was compromised mostly by highly educated women informal caregivers. This limits the generalizability of the research findings and encourages further evaluation of intervention effects for informal caregivers with a wider range of educational attainments. In addition, effects for the informal caregivers coming from different socioeconomic groups should also be explored. Previous research findings indicate unemployment, lower income and residing in deprived neighbourhoods to be associated with poorer psychological therapy outcomes (Finegan et al., 2018). Therefore, these factors should be considered in future recruitment and evaluation of the intervention.

\subsubsection{Outcome assessment}

Caregiver burden was chosen as the primary outcome measure in Study II. It was measured by the CBI (Novak \& Guest, 1989), a single self-report questionnaire. The caregiver burden is a complex experience that might be difficult to capture in a single self-report measure. The burden incorporates the strains from several domains and is a very individualized experience. 
The CBI views caregiver burden as a multidimensional experience consisting of five domains. Hence, even though CBI provides an opportunity to investigate which life areas are the most affected for informal caregivers, it is limited to these aspects only. Several measures and a more thorough evaluation might be required to evaluate the burden that informal caregivers experience.

The choice to focus on caregiver burden could be viewed as a limitation in itself. Researchers have previously expressed some criticism about the lack of focus on the positive aspects of caregiving (e.g., Marino et al., 2017). Exploration of positive caregiver experiences in our conducted studies could have helped gain additional insights into caregiver experiences and enrich existing literature of caregiving gains.

\subsubsection{Negative effects}

Previous research findings documented a small proportion of participants to experience deterioration in their well-being following the use of the ICBT (Ebert et al., 2016). Even though the therapists in Study II have engaged with participants and monitored the possibility of adverse events throughout the intervention, no formal assessment of negative effects was made. The use of open-ended questions could have helped to evaluate such experiences and inform further guidance in identifying the characteristics of the caregivers that might be prone to experience negative effects following ICBT.

\subsubsection{Contextual factors in Study II}

The main goal of Study II was to evaluate the effects of ICBT for reducing informal caregiver burden, depression, anxiety, and stress, as well as improving the perceived quality of life. One limitation of this study is that we did not control for contextual factors. For example, the help that the caregivers could have been possibly receiving from other family members, or their skills, or preparation to provide care. Further control of these factors should be implemented in following ICBT's assessment to distinguish for the effects of the intervention.

\subsubsection{Control group in Study II}

One possible limitation in Study II is the inclusion of a wait-list control group. Such control groups have been criticised for inflating effect sizes (Gold et al., 2017). Also, it has been criticised for potentially decreasing control group participant likelihood for searching for alternative treatment (Gold et al., 2017) as well as putting these participants at risk for 
experiencing nocebo effects (Furukawa et al., 2014). Despite that, due to the pilot nature of the trial, lack of existing resources for the informal caregivers and a high success rate of ICBT in other populations, a wait-list control condition was viewed as an appropriate comparator in this pilot study. Nevertheless, further evaluation of the intervention should be preferably conducted with either treatment as usual or face-to-face comparison control groups.

\subsubsection{Design of Study IV}

In comparison to Studies I-III, Study IV was conducted following a somehow less established methodology. That is, even though the suggestions by Moore et al. (2015) were followed, more flexibility in designing the process evaluation study was allowed. That is, a decision was made to conduct and merge two distinct research studies. In support of this decision, in their most recent update for complex intervention development and evaluation, Skivington et al. (2021) encouraged researchers to be innovative and flexible in testing their research questions. Therefore, in the case of Study IV, such an approach was deemed the most appropriate for exploring the suitability of the intervention and gaining perspective not only from the informal caregivers but also stakeholders.

On an additional note, the data used for Study IV could be considered limited. Only one focus group was included, and the obtained intervention evaluations were from a sub-sample in Study II. At the same time, stakeholder discussion resulted in several relevant themes depicting the intervention's potential. Also, informal caregiver evaluations and reflections provided additional information about its usability. Altogether, even if based on small samples, the data generated valuable insights. Nevertheless, further evaluation of the intervention should be preceded by another process evaluation study in which a higher number of informal caregivers and stakeholders, and preferably several stakeholder focus group discussions, should be conducted.

\subsubsection{Working mechanisms}

In Study II, moderate between-group effect sizes were found regarding caregiver burden, depression, and anxiety scores and high effect sizes for the reduction in stress and increase in the quality of life for the informal caregivers in the intervention group. Following Studies III and IV, it was possible to gain insight into which components of the intervention were the most valued by the participants. Despite that, the mechanisms responsible for the change in the informal caregiver well-being were not studied, and it 
is not possible to conclude what components of the intervention were the most beneficial, mainly due to the small sample size. Previous ICBT studies have considered some factors, such as therapeutic alliance (Andersson et al., 2012), to potentially act as mechanisms of change. Several mediators of outcome have also been considered, such as the user-friendliness of the intervention (Andersson et al., 2009). Also, the change in the dysfunctional thinking patterns (Márquez-González et al., 2007), as well as the increase in the engagement with enjoyable activities (Losada et al., 2011) as mediators for the reduction in depressive symptoms following CBT. Based on the effect sizes in Study II and participant experiences in Study III, it could be suggested that the most successful aspects of the ICBT intervention were the behavioural activation, the cognitive restructuring, and the therapeutic alliance. Further intervention's evaluation should focus on investigating the effects of these components as well as other possible working mechanisms.

\subsubsection{Therapist effects}

Regarding the therapeutic alliance, one additional limitation stems from the fact that we did not assess the frequency of the contact between the therapist and individual participant. The contact with the therapist could have influenced the caregiver outcomes. Short therapist training and weekly supervision were conducted to standardise (as much as possible) the manner of communication and the structure of the therapist messages. Nevertheless, possible therapist effects should not be discounted. Future studies should aim to control these effects and potentially investigate Lithuanian informal caregiver experiences of therapist contact in the ICBT setting.

\subsubsection{COVID-19 influence in Study I}

Study I was conducted during the first months of the COVID-19 pandemic. Several research articles have documented not only the well-being of the informal caregivers (e.g., Altieri \& Santangelo, 2021) but also the general population (e.g., Brodeur et al., 2021) to be negatively affected by the pandemic. Therefore, it could be expected that the stresses caused by the pandemic could have reflected upon the participant responses. 


\subsection{FUTURE DIRECTIONS}

This thesis described the first attempt to adapt and evaluate an internet intervention for informal caregivers in Lithuania. Due to the pilot nature of this work, several future directions should be considered. Most importantly, further development of the intervention should be conducted. In addition, and as discussed in the limitation section, research emphasis should also be placed on investigating the intervention's working mechanisms. Apart from these two aspects, several other future directions could be considered. I will briefly reflect on them in the following paragraphs.

\subsubsection{Focusing on the dyad}

The ICBT was designed to be used by the informal caregiver. One of the future directions could be to incorporate the care-receiver and focus on the caregiver-care-receiver dyad instead. Even though it is evident that the relationship between the members of the dyad can influence their well-being (Pristavec, 2019), research exploring the dyadic perspective in caregiving is still relatively scarce. ICBT has been previously considered for use in the dyadic setting (Gawlytta et al., 2020), and some more research is currently underway (Akkol-Solakoglu et al., 2021), encouraging its adaptation in the informal caregiving setting.

\subsubsection{Collecting long-term outcomes}

In addition to the further intervention's development and evaluation, longterm effects should be evaluated. In general, there is some evidence to indicate that ICBT maintains its effects over time (Andersson et al., 2018). At the same time, the evidence is somehow limited, and further knowledge is needed. Therefore, future research efforts should be focused on evaluating the outcomes over time. This could be done by collecting follow-up data within six or more months after the completion of the intervention (Wiegelmann et al., 2021).

\subsubsection{Exploring diversity}

One of the goals of this research was to evaluate the suitability of ICBT and its potential for the Lithuanian informal caregivers overall, beyond our collected sample. Even though generalization of the findings is desirable, it might also run a risk of undermining informal caregiver diversity. Therefore, two recommendations for future research could be given. Firstly, further research efforts should be placed on investigating the diversity among informal caregivers. In a recent scoping review, Hengelaar et al. (2021) suggested employing an intersectional perspective in caregiver 
research that would account for various caregiver and care-receiver characteristics. That is, accounting for the diversity in the caregiver and care-receiver as well as the various contextual factors such as historical, cultural, and societal influences.

Previous research outlined difficulty in recruiting ethnic minority informal caregivers (e.g., Chadiha et al., 2004) as well as a lack of knowledge and inclusion of, for example, informal caregivers of chronically ill lesbian, gay, and bisexual (LGB) adults (Fredriksen-Goldsen et al., 2009). Some of the strategies for recruiting diverse informal caregiver samples could include involving a diverse research team and using multiple recruitment strategies (e.g., flyers and social media) (Webber-Ritchey et al., 2021). Engaging with the informal caregiver communities and requesting the assistance of the community members could be another approach in addition to the development and the use of non-stigma-inducing language in the recruitment materials (Ellard-Gray et al., 2015).

Secondly, as evident from the findings of Studies II-IV, not all informal caregivers equally benefit from the intervention. Therefore, a closer investigation of the diversity of the informal caregivers could help to identify characteristics of the caregivers for whom the internet interventions might be the most beneficial. On a related note, since we did not distinguish between caregivers concerning their living situation (residing with the caregiver versus living separately) or, for example, the type of support that caregivers were receiving, future research could focus on evaluating intervention effects for these groups of informal caregivers separately. Existing research points out that these groups of caregivers might differ in the type of challenges as well as the outcomes of the caregiving experienced (e.g., Li et al., 2019). Accordingly, intervention components might need to be adjusted respectively.

\subsubsection{Exploring the cultural context}

In the planning of Study II, we had several discussions regarding the term informal caregivers. Some similar phrases to the English term exist in the Lithuanian language; however, there seem to be none to depict it straightforwardly and clearly. Therefore, we decided to choose the phrase 'I take care of my close one'. This is also how the intervention was named. Therefore, one suggestion for future studies could be to explore the meaning of this phrase in the Lithuanian context. Qualitative interviews or focus group discussions with the informal caregivers or stakeholders could help identify the meaning and the relevant associations. On an additional note, previous findings indicated that individuals taking care of their close ones 
might not necessarily identify themselves as informal caregivers (e.g., Hughes et al., 2013; Smyth et al., 2011). Therefore, exploring relevant terminology and corresponding values or associations could help identify and approach informal caregivers.

\subsubsection{Exploring the meaning of the change}

The findings of Studies III and IV have been very useful in understanding how informal caregivers experienced using the intervention. Despite that, some questions remain. To give an example, probably one of the more interesting findings from Study II was the reduction in the scores on the Physical health and Development subscales of the CBI measure. Especially the reduction in the Physical health subscale of CBI since it depicts a more physical side of the burden, such as tiredness and sleep disturbances. One way to answer such questions would be to investigate participant experiences applying the interventions materials in their daily lives. Also, gaining insights into what changes they experienced and how such changes manifested in reduced burden or improved well-being. The latter could also help in understanding the working mechanisms of the intervention. Especially given that the current knowledge regarding change mechanisms and moderators as well as mediators of ICBT effects is very limited (Andersson et al., 2019; Mogoașe et al., 2017).

\subsubsection{Exploring further use of the intervention}

One relevant question to be answered by future researchers relates to the potential of ICBT in either preventing or alleviating the negative mental health outcomes of the informal caregivers. To be eligible for participation in Study II, informal caregivers had to be experiencing caregiver burden. Based on the moderate to high effect sizes for the reduction in caregiver burden, anxiety, depression, stress and increase in the quality of life as indicated by Study II findings, current ICBT has the potential in improving already existent negative psychological health symptoms. However, it could be argued that the intervention could provide informal caregivers with psychoeducational information and skills that, if applied, would also be potentially useful for preventing the occurrence of these negative outcomes. Therefore, one question to be answered by future research is if ICBT could be equally useful as a preventative and as a curative means of support for informal caregivers. 


\subsection{PRACTICAL IMPLICATIONS}

To start with, this research work has provided insight into Lithuanian informal caregiver characteristics. Throughout the conducted research studies, participants were able to share their stories and raise their concerns. Such knowledge adds to the existing literature by enriching understanding of caregiving trends, challenges, and support needs.

Study findings also provided evidence regarding ICBT's suitability for Lithuanian informal caregivers. Since internet intervention studies in Lithuania are still relatively scarce, these findings encourage further investigation into ICBT's suitability for informal caregivers as well as different target groups. 


\section{CONCLUSIONS}

Study I showed that Lithuanian informal caregivers experience a high burden and the need for support. Study II indicated that ICBT can be effective in reducing informal caregiver burden, depression, anxiety, stress and increasing the quality of life. Following the interviews with the participants, Study III outlined that informal caregivers were overall positive about the intervention and perceived it as acceptable. In this study, several suggestions regarding possible ICBT's development were also outlined. Lastly, Study IV brought new insights about the suitability of the intervention in terms of its functionality as perceived by the informal caregivers and as perceived by a group of stakeholders.

In conclusion, Lithuanian informal caregivers were found to experience a need for more support. In turn, ICBT was found to be suitable for providing Lithuanian informal caregivers with psychological support. Since these findings are mostly based on small-scale pilot results, further research studies are required. Future research should also aim to identify the mechanisms behind the intervention effectiveness and the characteristics of informal caregivers who benefit from ICBT. 


\section{Acknowledgements}

Completing of this thesis was possible due to the efforts, help and support of many people. I appreciate your help, support, and belief in me dearly.

A great thank you to Gerhard Andersson for teaching and guiding me throughout this process. I am very grateful for the opportunity to learn from you. Your help and support have contributed greatly to both the completion of this work as well as my personal growth.

I extend my gratitude to my supervisor Evaldas Kazlauskas who has first, very willingly accepted the proposal for collaboration on this project and has provided great support and supervision ever since. I am very thankful for your help and vast input into this project. Also, for the initiative of involving members of your research team without whom the completion of this project would have been impossible.

My heartfelt gratitude extends to my supervisor Robbert Sanderman, who has been a great source of encouragement as well as academic support. Your guidance and inputs have helped this project to grow. Thank you for always being so positive and supportive.

My gratefulness extends to Austėja Dumarkaite, who has joined this project from the very start and supported it throughout the years. Your hard work, support, and kindness have helped in completing this work and enriched the whole experience.

I would also like to thank Inga Truskauskaite-Kunevičiene, who has helped immensely in setting up this project and has kindly offered her help and support throughout.

My sincere thankfulness for George Vlaescu. Thank you for your hard work, kindness, and patience in setting the intervention up as well as during numerous meetings and discussions. It has been a pleasure to work with you.

I also thank Vaiva Milašiūnaite and Julija Mingaudaite, who has helped greatly in evaluating the intervention. Also, Irma Sabonyte who has contributed to the intervention's evaluation and the planning of the process evaluation study. Your efforts and presence made the completion of the research work possible and made it very enjoyable. 
I highly appreciate the advice and feedback from Ghassan Mourad and Val Morrison during the $60 \%$ and $90 \%$ seminars. Thank you for your time and inputs that have helped improve the articles and the thesis immensely.

My sincere thankfulness to all the participants in the conducted research studies. Thank you for the opportunity to learn about your experiences.

Thank you to the reviewers of the four research articles. I value greatly the comments and the suggestions that you have kindly provided.

A warm thanks to my fellow PhD student at Linköping University: Hajdi, Anton, Nathalie, Tomas, Matilda, Örn, Victoria, Mikael, Per, Sandra, and Line. Your presence, friendship, support, and conversations were a huge driving force.

A special thank you to my dear friends Miko, Chelsea, Rodrigo, Maiara, Valeska and Ingel. Thank you for the newly established friendships and your support throughout this journey.

This project would not have been possible without the funding from the European Union's Horizon 2020 research and innovation programme under the Marie Skłodowska-Curie grant agreement No 814072 and as part of The European Training Network on Informal Care (ENTWINE).

My sincere thank you to all the members of ENTWINE for all the meetings and training provided throughout the years.

A special thanks to my fellow PhD students at ENTWINE- you have turned the $\mathrm{PhD}$ process into a very enjoyable experience, and your support was extremely valuable and appreciated.

Thank you to my parents, Daiva and Vytautas, my sisters Lina and Vaiva and their families. You are my inspiration and the greatest driving force.

(Dékoju tèveliams Daivai ir Vytautui, seserims Linai ir Vaivai bei ju šeimoms. Jūs esate mano ịkvépimas ir didžiausia varomoji jëga.)

Thank you for my Daniël for the love, the support, and the belief in me. And thank you to my dear babyte, my wonderful grandmother. For all the loving years, among many things. You are forever in my heart. 


\section{Trumpa santrauka lietuviškai}

Visuomenèje vis daugèja žmonių, kurie slaugo savo artimuosius. Galimybė rūpintis ir slaugyti artimajji gali suteikti daug malonių bei praturtinančių jausmų. Visgi tai gali pareikalauti nemažai pastangų ir laiko. Dèl šios priežasties svarbu pasirūpinti, kad žmonėms, kurie slaugo savo artimuosius ir dèl to patiria emocinių sunkumų, tokių kaip nerimas ar padidèjęs streso lygis, būtų suteikta tinkama psichologinè parama. Ankstesnių mokslinių tyrimų duomenimis, internetinès intervencijos, sukurtos pagal kognityvinès elgesio terapijos (KET) principus, gali būti veiksmingos suteikiant psichologinę pagalbą asmenims, kurie slaugo savo artimuosius.

Pagrindinis šio doktorantūros darbo tikslas buvo įvertinti, ar internetinė KET principais pagrịsta intervencija gali būti tinkama suteikiant psichologinę paramą lietuviams, kurie slaugo savo artimuosius. Taip pat buvo siekta surinkti informaciją apie žmonių, slaugančiujų artimuosius, charakteristikas, ịvertinti jų patiriamą naštą bei pagalbos poreikị. Šiems tyrimo tikslams igyvendinti buvo atlikti keturi moksliniai tyrimai.

Pirmajame šioje disertacijoje aprašytame tyrime pristatomi apklausos duomenys. Apklausa buvo skirta ịvertinti artimuosius slaugančių lietuvių poreikius bei patiriamą naštą. Šioje apklausoje dalyvavo 226 asmenys. Rezultatai parodè, kad dauguma artimuosius slaugančių lietuvių patiria sunkumų ir norètų gauti daugiau paramos slaugant savo artimajị.

Antrasis tyrimas buvo skirtas ịvertinti internetinès intervencijos, sukurtos remiantis KET principais, veiksmingumą. Šiame tyrime dalyvavo 63 savo artimuosius slaugantys asmenys. Dalyviai aštuonias savaites naudojosi internetine programa. Prieš intervenciją ir po naudojimosi ja dalyviai užpilde keletą klausimynų, kuriais buvo vertinama jų savijauta. Tyrimo rezultatai parodè, kad po naudojimosi programa dalyviai patyrè mažiau depresijos, nerimo, streso bei bendros slaugymo naštos simptomų. Taip pat pagerejo jų bendra gyvenimo kokybè.

Trečiasis tyrimas buvo skirtas papildomai įvertinti intervenciją. Šiuo tyrimu buvo siekiama apklausti antrojo tyrimo dalyvius apie tai, kaip jiems sekèsi naudotis KET principais paremta internetine intervencija. Telefoniniuose interviu dalyvavo 23 dalyviai; jie pasidalino savo patirtimi apie naudojimąsi programa. Atlikus kokybinę duomenų analizę paaiškèjo, kas dalyviams intervencijoje patiko ir ką būtų galima patobulinti. Be to, buvo nustatyti 
veiksniai, kurie prisideda prie slaugančiujų gerovès ir galètų būti reikšmingi toliau plètojant intervenciją.

Ketvirtasis ir paskutinysis tyrimas buvo skirtas dar plačiau įvertinti intervenciją. Šio tyrimo metu buvo analizuoti prieš tai nenaudoti dalyvių intervencijos įvertinimo rodikliai. Taip pat buvo suorganizuota diskusija, kurios metu aštuoni specialistai, turintys patirties slaugymo kontekste, pasidalino savo ịžvalgomis apie intervencinès programos tinkamumą. Rezultatai parodè, kad intervencija potencialiai yra tinkama teikiant psichologinę paramą savo artimuosius slaugantiems lietuviams. Kaip ir ankstesni tyrimai, šio tyrimo rezultatai taip pat parodè, kad keletas intervencijos aspektụ galètų būti patobulinti, kad intervencija būtų veiksmingesnè. Vienas iš tokių aspektų yra papildomos informacijos suteikimas bei galimybė gyvai konsultuotis su psichologu.

Apibendrinant, Lietuvoje savo artimuosius slaugantys žmonès norètų sulaukti daugiau su slaugymu susijusios visokeriopos pagalbos. Atliktu tyrimu duomenimis, KET principais pagrịsta internetinè intervencija galètų būti vienas iš tinkamų būdų suteikiant psichologinę pagalbą. Atliekant tolesnius tyrimus, galètų būti pakoreguota programa ir pakartotinai ịvertintas jos tinkamumas.

Reikšminiai žodžiai: artimuju slaugymas; slaugymo našta; internetinė intervencija; kognityvinė elgesio terapija. 


\section{References}

Akkol-Solakoglu, S., Hevey, D., \& Richards, D. (2021). A randomised controlled trial comparing internet-delivered cognitive behavioural therapy (iCBT) with and without main carer access versus treatment-as-usual for depression and anxiety among breast cancer survivors: Study protocol. Internet Interventions, 24, 100367. https://doi.org/10.1016/j.invent.2021.100367

Altieri, M., \& Santangelo, G. (2021). The psychological impact of COVID-19 pandemic and lockdown on caregivers of people with dementia. The American Journal of Geriatric Psychiatry, 29, 27-34. https://doi.org/10.1016/j.jagp.2020.10.009

Alvira, M. C., Risco, E., Cabrera, E., Farré, M., Rahm Hallberg, I., Bleijlevens, M. H., Meyer, G., Koskenniemi, J., Soto, M. E., \& Zabalegui, A. (2015). The association between positive-negative reactions of informal caregivers of people with dementia and health outcomes in eight European countries: a cross-sectional study. Journal of Advanced Nursing, 71(6), 1417-1434. https://doi.org/10.1111/jan.12528

Andersson, G. (2015a). The internet and CBT: A clinical guide. CRC Press.

Andersson, G. (2015b). Clinician-supported internet-delivered psychological treatment of tinnitus. American Journal of Audiology, 24(3), 299-301. https://doi.org/10.1044/2015_AJA-14-0080

Andersson, G. (2016). Internet-delivered psychological treatments. Annual Review of Clinical Psychology, 12, 157-179. https://doi.org/10.1146/annurevclinpsy-021815-093006

Andersson, G., Carlbring, P., Berger, T., Almlöv, J., \& Cuijpers, P. (2009). What makes internet therapy work? Cognitive Behaviour Therapy, 38(S1), 55-60. https://doi.org/10.1080/16506070902916400

Andersson, G., Carlbring, P., Holmström, A., Sparthan, E., Furmark, T., NilssonIhrfelt, E., Buhrman, M., \& Ekselius, L. (2006). Internet-based self-help with therapist feedback and in vivo group exposure for social phobia: a randomized controlled trial. Journal of Consulting and Clinical Psychology, 74(4), 677-686. https://doi.org/10.1037/0022-006X.74.4.677

Andersson, G., Paxling, B., Roch-Norlund, P., Östman, G., Norgren, A., Almlöv, J., Georén, L., Breitholtz, E., Dahlin, M., \& Cuijpers, P. (2012). Internet-based 
psychodynamic versus cognitive behavioral guided self-help for generalized anxiety disorder: a randomized controlled trial. Psychotherapy and Psychosomatics, 81(6), 344-355. https://doi.org/10.1159/000339371

Andersson, G., Paxling, B., Wiwe, M., Vernmark, K., Felix, C. B., Lundborg, L., Furmark, T., Cuijpers, P., \& Carlbring, P. (2012). Therapeutic alliance in guided internet-delivered cognitive behavioural treatment of depression, generalized anxiety disorder and social anxiety disorder. Behaviour Research and Therapy, 50(9), 544-550. https://doi.org/10.1016/j.brat.2012.05.003

Andersson, G., Rozental, A., Shafran, R., \& Carlbring, P. (2018). Long-term effects of internet-supported cognitive behaviour therapy. Expert Review of Neurotherapeutics, 18(1), 21-28. https://doi.org/10.1080/14737175.2018.1400381

Andersson, G., Titov, N., Dear, B. F., Rozental, A., \& Carlbring, P. (2019). Internet-delivered psychological treatments: from innovation to implementation. World Psychiatry, 18(1), 20-28. https://doi.org/10.1002/wps.20610

Barnett, A. E. (2015). Adult child caregiver health trajectories and the impact of multiple roles over time. Research on Aging, 37(3), 227-252. https://doi.org/10.1177/0164027514527834

Baumeister, H., Reichler, L., Munzinger, M., \& Lin, J. (2014). The impact of guidance on Internet-based mental health interventions - A systematic review. Internet Interventions, 1(4), 205-215. https://doi.org/10.1016/j.invent.2014.08.003

Beauchamp, N., Irvine, A. B., Seeley, J., \& Johnson, B. (2005). Worksite-based internet multimedia program for family caregivers of persons with dementia. The Gerontologist, 45(6), 793-801. https://doi.org/10.1093/geront/45.6.793

Bertrand, R. M., Saczynski, J. S., Mezzacappa, C., Hulse, M., Ensrud, K., \& Fredman, L. (2012). Caregiving and cognitive function in older women: Evidence for the healthy caregiver hypothesis. Journal of Aging and Health, 24(1), 48-66. https://doi.org/10.1177/0898264311421367

Bhan, N., Rao, N., \& Raj, A. (2020). Gender differences in the associations between informal caregiving and wellbeing in low-and middle-income countries. Journal of Women's Health, 29(10), 1328-1338. https://doi.org/10.1089/jwh.2019.7769 
Biegel, D. E., Sales, E., \& Schulz, R. (1991). Family caregiving in chronic illness: Alzheimer's disease, cancer, heart disease, mental illness, and stroke. Sage Publications, Inc.

Blair, E. (2015). A reflexive exploration of two qualitative data coding techniques. Journal of Methods and Measurement in the Social Sciences, 6(1), 14-29. https://doi.org/10.2458/v6i1.18772

Blom, M. M., Zarit, S. H., Groot Zwaaftink, R. B., Cuijpers, P., \& Pot, A. M. (2015). Effectiveness of an Internet intervention for family caregivers of people with dementia: results of a randomized controlled trial. PloS one, 10(2), e0116622. https://doi.org/10.1371/journal.pone.0116622

Bookwala, J. (2009). The impact of parent care on marital quality and well-being in adult daughters and sons. Journals of Gerontology: Series B, 64(3), 339347. https://doi.org/10.1093/geronb/gbp018

Braun, V., \& Clarke, V. (2006). Using thematic analysis in psychology. Qualitative Research in Psychology, 3(2), 77-101. DOI: 10.1191/1478088706qp063oa

Braun, V., \& Clarke, V. (2020). One size fits all? What counts as quality practice in (reflexive) thematic analysis? Qualitative Research in Psychology, 1-25. https://doi.org/10.1080/14780887.2020.1769238

Brodaty, H., \& Donkin, M. (2009). Family caregivers of people with dementia. Dialogues in Clinical Neuroscience, 11(2), 217. doi: 10.31887/DCNS.2009.11.2/hbrodaty

Brodaty, H., Woodward, M., Boundy, K., Ames, D., Balshaw, R., \& Group, P. S. (2014). Prevalence and predictors of burden in caregivers of people with dementia. The American Journal of Geriatric Psychiatry, 22(8), 756-765. https://doi.org/10.1016/j.jagp.2013.05.004

Brodeur, A., Clark, A. E., Fleche, S., \& Powdthavee, N. (2021). COVID-19, lockdowns and well-being: Evidence from Google trends. Journal of Public Economics, 193, 104346. https://doi.org/10.1016/j.jpubeco.2020.104346

Brouwer, W. B., van Exel, N. J. A., van den Berg, B., van den Bos, G. A., \& Koopmanschap, M. A. (2005). Process utility from providing informal care: the benefit of caring. Health Policy, 74(1), 85-99. https://doi.org/10.1016/j.healthpol.2004.12.008 
Brown, R. M., \& Brown, S. L. (2014). Informal caregiving: A reappraisal of effects on caregivers. Social Issues and Policy Review, 8(1), 74-102. https://doi.org/10.1111/sipr.12002

Brown, S. L., \& Brown, R. M. (2006). Selective investment theory: Recasting the functional significance of close relationships. Psychological Inquiry, 17(1), 1-29. https://doi.org/10.1207/s15327965pli1701_01

Calvó-Perxas, L., Vilalta-Franch, J., Litwin, H., Turró-Garriga, O., Mira, P., \& Garre-Olmo, J. (2018). What seems to matter in public policy and the health of informal caregivers? A cross-sectional study in 12 European countries. PloS one, 13(3), e0194232. https://doi.org/10.1371/journal.pone.0194232

Capistrant, B. D., Moon, J. R., \& Glymour, M. M. (2012). Spousal caregiving and incident hypertension. American Journal of Hypertension, 25(4), 437-443. https://doi.org/10.1038/ajh.2011.232

Capistrant, B. D., Moon, J. R., Berkman, L. F., \& Glymour, M. M. (2012). Current and long-term spousal caregiving and onset of cardiovascular disease.

Journal of Epidemiology \& Community Health, 66(10), 951-956. . doi:10.1136/jech-2011-200040

Carbonneau, H., Caron, C., \& Desrosiers, J. (2010). Development of a conceptual framework of positive aspects of caregiving in dementia. Dementia, 9(3), 327-353. https://doi.org/10.1177/1471301210375316

Carlbring, P., Andersson, G., Cuijpers, P., Riper, H., \& Hedman-Lagerlöf, E. (2018). Internet-based vs. face-to-face cognitive behavior therapy for psychiatric and somatic disorders: an updated systematic review and metaanalysis. Cognitive Behaviour Therapy, 47(1), 1-18. https://doi.org/10.1080/16506073.2017.1401115

Caserta, M. S., Lund, D. A., \& Wright, S. D. (1996). Exploring the Caregiver Burden Inventory (CBI): further evidence for a multidimensional view of burden. The International Journal of Aging and Human Development, 43(1), 21-34. https://doi.org/10.2190/2DKF-292P-A53W-W0A8

Chadiha, L. A., Morrow-Howell, N., Proctor, E. K., Picot, S. J. F., Gillespie, D. C., Pandey, P., \& Dey, A. (2004). Involving rural, older African Americans and their female informal caregivers in research. Journal of Aging and Health, 16(5_suppl), 18S-38S. https://doi.org/10.1177/0898264304268147 
Chen, F.-p., \& Greenberg, J. S. (2004). A positive aspect of caregiving: The influence of social support on caregiving gains for family members of relatives with schizophrenia. Community Mental Health Journal, 40(5), 423-435. https://doi.org/10.1023/B:COMH.0000040656.89143.82

Cherak, S. J., Rosgen, B. K., Amarbayan, M., Wollny, K., Doig, C. J., Patten, S. B., Stelfox, H. T., \& Fiest, K. M. (2021). Mental health interventions to improve psychological outcomes in informal caregivers of critically ill patients: A systematic review and meta-analysis. Critical Care Medicine, 49(9), 1414-1426. DOI: 10.1097/CCM.0000000000005011

Cohen, S., Kamarck, T., \& Mermelstein, R. (1983). A global measure of perceived stress. Journal of Health and Social Behavior, 24(4), 385-396. https://pubmed.ncbi.nlm.nih.gov/6668417/

Çoklar, A. N., \& Tatli, A. (2021). Examining the digital nativity levels of digital generations: from generation $\mathrm{X}$ to generation $\mathrm{Z}$. Shanlax International Journal of Education, 9(4), 433-444. https://doi.org/10.34293/education.v9i4.4224

Coon, D. W., Thompson, L., Steffen, A., Sorocco, K., \& Gallagher-Thompson, D. (2003). Anger and depression management: psychoeducational skill training interventions for women caregivers of a relative with dementia. The Gerontologist, 43(5), 678-689. https://doi.org/10.1093/geront/43.5.678

del-Pino-Casado, R., Frías-Osuna, A., Palomino-Moral, P. A., \& Ramón MartínezRiera, J. (2012). Gender differences regarding informal caregivers of older people. Journal of Nursing Scholarship, 44(4), 349-357. https://doi.org/10.1111/j.1547-5069.2012.01477.x

Doblytė, S. (2020). Shame in a post-socialist society: a qualitative study of healthcare seeking and utilisation in common mental disorders. Sociology of Health \& Illness, 42(8), 1858-1872. https://doi.org/10.1111/14679566.13170

Doblyte, S. (2021). Power dynamics of the healthcare field: seeking mental care in Lithuania. Journal of Baltic Studies, 52(3), 1-16. https://doi.org/10.1080/01629778.2021.1934053

Duggleby, W., Ploeg, J., McAiney, C., Fisher, K., Swindle, J., Chambers, T., Ghosh, S., Peacock, S., Markle-Reid, M., \& Triscott, J. (2017). Study protocol: pragmatic randomized control trial of an internet-based 
intervention (My tools 4 care) for family carers. BMC Geriatrics, 17(1), 1-9. https://doi.org/10.1186/s12877-017-0581-6

Dumarkaite, A., Truskauskaite-Kuneviciene, I., Andersson, G., Mingaudaite, J., \& Kazlauskas, E. (2021). Effects of mindfulness-based internet intervention on ICD-11 posttraumatic stress disorder and complex posttraumatic stress disorder symptoms: a pilot randomized controlled trial. Mindfulness, 12(11), 2754-2766. https://doi.org/10.1007/s12671-021-01739-w

Ebert, D., Donkin, L., Andersson, G., Andrews, G., Berger, T., Carlbring, P., Rozenthal, A., Choi, I., Laferton, J., \& Johansson, R. (2016). Does Internetbased guided-self-help for depression cause harm? An individual participant data meta-analysis on deterioration rates and its moderators in randomized controlled trials. Psychological Medicine, 46(13), 2679-2693. doi:10.1017/S0033291716001562

Eimontas, J., Rimsaite, Z., Gegieckaite, G., Zelviene, P., \& Kazlauskas, E. (2018). Internet-based self-help intervention for ICD-11 adjustment disorder: preliminary findings. Psychiatric Quarterly, 89(2), 451-460. https://doi.org/10.1007/s11126-017-9547-2

Ellard-Gray, A., Jeffrey, N. K., Choubak, M., \& Crann, S. E. (2015). Finding the hidden participant: Solutions for recruiting hidden, hard-to-reach, and vulnerable populations. International Journal of Qualitative Methods, 14(5), 1609406915621420. https://doi.org/10.1177/1609406915621420

Elliott, T. R., \& Parker, M. (2012). Family caregivers and health care providers: Developing partnerships for a continuum of care and support. In Multiple dimensions of caregiving and disability (pp. 135-152). Springer.

Etzelmueller, A., Vis, C., Karyotaki, E., Baumeister, H., Titov, N., Berking, M., Cuijpers, P., Riper, H., \& Ebert, D. D. (2020). Effects of internet-based cognitive behavioral therapy in routine care for adults in treatment for depression and anxiety: Systematic review and meta-analysis. Journal of Medical Internet Research, 22(8), e18100. doi:10.2196/18100

Eurostat (2021). Eurostat regional yearbook (2021 edition). Luxembourg: Publications Office of the European Union, 2021. doi:10.2785/894358.

Fair Internet Report (2020). Retrieved on the $17^{\text {th }}$ of December 2021. Available at: https://fairinternetreport.com/research/internet-speed-by-country 
Finegan, M., Firth, N., Wojnarowski, C., \& Delgadillo, J. (2018). Associations between socioeconomic status and psychological therapy outcomes: A systematic review and meta-analysis. Depression and Anxiety, 35(6), 560573. https://doi.org/10.1002/da.22765

Forand, N. R., Barnett, J. G., Strunk, D. R., Hindiyeh, M. U., Feinberg, J. E., \& Keefe, J. R. (2018). Efficacy of guided iCBT for depression and mediation of change by cognitive skill acquisition. Behavior Therapy, 49(2), 295-307. https://doi.org/10.1016/j.beth.2017.04.004

Fredriksen-Goldsen, K. I., Kim, H.-J., Muraco, A., \& Mincer, S. (2009).

Chronically ill midlife and older lesbians, gay men, and bisexuals and their informal caregivers: The impact of the social context. Sexuality Research and Social Policy Journal of NSRC, 6(4), 52-64. https://doi.org/10.1525/srsp.2009.6.4.52

Furukawa, T., Noma, H., Caldwell, D., Honyashiki, M., Shinohara, K., Imai, H., Chen, P., Hunot, V., \& Churchill, R. (2014). Waiting list may be a nocebo condition in psychotherapy trials: a contribution from network metaanalysis. Acta Psychiatrica Scandinavica, 130(3), 181-192. https://doi.org/10.1111/acps.12275

Gawlytta, R., Brunkhorst, F., Niemeyer, H., Boettche, M., Knaevelsrud, C., \& Rosendahl, J. (2020). Dyadic post-traumatic stress after intensive care: Case report of a sepsis patient and his wife. Intensive and Critical Care Nursing, 58, 102806. https://doi.org/10.1016/j.iccn.2020.102806

Geng, H.-m., Chuang, D.-m., Yang, F., Yang, Y., Liu, W.-m., Liu, L.-h., \& Tian, H.-m. (2018). Prevalence and determinants of depression in caregivers of cancer patients: A systematic review and meta-analysis. Medicine, 97(39): e11863. doi: 10.1097/MD.0000000000011863

Gold, S. M., Enck, P., Hasselmann, H., Friede, T., Hegerl, U., Mohr, D. C., \& Otte, C. (2017). Control conditions for randomised trials of behavioural interventions in psychiatry: a decision framework. The Lancet Psychiatry, 4(9), 725-732. https://doi.org/10.1016/S2215-0366(17)30153-0

Guay, C., Auger, C., Demers, L., Mortenson, W. B., Miller, W. C., GélinasBronsard, D., \& Ahmed, S. (2017). Components and outcomes of internetbased interventions for caregivers of older adults: systematic review. Journal of Medical Internet Research, 19(9), e313. doi: 10.2196/jmir.7896 
Gupta, S. K. (2011). Intention-to-treat concept: a review. Perspectives in Clinical Research, 2(3), 109-112. DOI: 10.4103/2229-3485.83221

Hagedoorn, M., Sanderman, R., Bolks, H. N., Tuinstra, J., \& Coyne, J. C. (2008). Distress in couples coping with cancer: a meta-analysis and critical review of role and gender effects. Psychological Bulletin, 134(1), 1-30. doi: 10.1037/0033-2909.134.1.1

Hengelaar, A. H., Wittenberg, Y., Kwekkeboom, R., Van Hartingsveldt, M., \& Verdonk, P. (2021). Intersectionality in informal care research: a scoping review. Scandinavian Journal of Public Health, 14034948211027816. https://doi.org/10.1177/14034948211027816

Hermanns, M., \& Mastel-Smith, B. (2012). Caregiving: A Qualitative Concept Analysis. Qualitative Report, 17(38), 1-18. DOI: 10.46743/2160$3715 / 2012.1727$

Hughes, N., Locock, L., \& Ziebland, S. (2013). Personal identity and the role of 'carer'among relatives and friends of people with multiple sclerosis. Social Science \& Medicine, 96, 78-85.

https://doi.org/10.1016/j.socscimed.2013.07.023

Jacobson, N. S., \& Truax, P. (1992). Clinical significance : A statistical approach to defining meaningful change in psychotherapy research. In A. E. Kazdin (Ed.), Methodological Issues \& Strategies in Clinical Research (pp. 631648). American Psychological Association. https://doi.org/10.1037/10109042

Jakobsen, J. C., Gluud, C., Wetterslev, J., \& Winkel, P. (2017). When and how should multiple imputation be used for handling missing data in randomised clinical trials-a practical guide with flowcharts. BMC Medical Research Methodology, 17(1), 162. https://doi.org/10.1186/s12874-017-0442-1

Johansson, L. (1991). Caring for the next of kin: On informal care of the elderly in Sweden [Doctoral dissertation, Uppsala University]. Uppsala: Acta Universitatis Upsaliensis. DiVA. https://www.divaportal.org/smash/record.jsf?pid=diva2\%3A294776\&dswid=9993

Kaddour, L., Kishita, N., \& Schaller, A. (2019). A meta-analysis of low-intensity cognitive behavioral therapy-based interventions for dementia caregivers. International Psychogeriatrics, 31(7), 961-976.

doi:10.1017/S1041610218001436 
Kajiyama, B., Thompson, L. W., Eto-Iwase, T., Yamashita, M., Di Mario, J., Marian Tzuang, Y., \& Gallagher-Thompson, D. (2013). Exploring the effectiveness of an internet-based program for reducing caregiver distress using the iCare Stress Management e-Training Program. Aging \& Mental Health, 17(5), 544-554. https://doi.org/10.1080/13607863.2013.775641

Kishita, N., Hammond, L., Dietrich, C. M., \& Mioshi, E. (2018). Which interventions work for dementia family carers?: an updated systematic review of randomized controlled trials of carer interventions. International Psychogeriatrics, 30(11), 1679-1696. doi:10.1017/S1041610218000947

Kramer, B. J. (1997). Differential predictors of strain and gain among husbands caring for wives with dementia. The Gerontologist, 37(2), 239-249. https://doi.org/10.1093/geront/37.2.239

Kroenke, K., Spitzer, R. L., \& Williams, J. B. (2001). The PHQ-9: validity of a brief depression severity measure. Journal of General Internal Medicine, 16(9), 606-613. https://doi.org/10.1046/j.1525-1497.2001.016009606.x

Kudukytè-Gasperè, R., \& Jankauskienė, D. (2015). Integruotos sveikatos priežiūros paslaugos-i žmonių poreikius orientuotos sveikatos priežiūros sistemos skatinimas Europos regione. Health Policy and Management, 2(7), 113-133. doi:10.13165/SPV-14-2-7-07

Lawton, M. P., Kleban, M. H., Moss, M., Rovine, M., \& Glicksman, A. (1989). Measuring caregiving appraisal. Journal of Gerontology, 44(3), P61-P71. https://doi.org/10.1093/geronj/44.3.P61

Lazarus, R. S., \& Folkman, S. (1984). Stress, appraisal, and coping. Springer publishing company.

Lee, M., Ryoo, J. H., Chung, M., Anderson, J. G., Rose, K., \& Williams, I. C. (2020). Effective interventions for depressive symptoms among caregivers of people with dementia: A systematic review and meta-analysis. Dementia, 19(7), 2368-2398. https://doi.org/10.1177/1471301218822640

Li, M., Mao, W., Chi, I., \& Lou, V. W. (2019). Geographical proximity and depressive symptoms among adult child caregivers: Social support as a moderator. Aging \& Mental Health, 23(2), 205-213. https://doi.org/10.1080/13607863.2017.1399349 
Li, Q., \& Loke, A. Y. (2013). The positive aspects of caregiving for cancer patients: a critical review of the literature and directions for future research. Psychooncology, 22(11), 2399-2407. https://doi.org/10.1002/pon.3311

Lindner, P., Frykheden, O., Forsström, D., Andersson, E., Ljótsson, B., Hedman, E., Andersson, G., \& Carlbring, P. (2016). The Brunnsviken Brief Quality of life scale (BBQ): Development and psychometric evaluation. Cognitive Behaviour Therapy, 45(3), 182-195. https://doi.org/10.1080/16506073.2016.1143526

Liubinienè, V., \& Thunqvist, D. P. (2015). Media literacy and digital divide: A cross-cultural case study of Sweden and Lithuania. Creativity Studies, 8(2), 134-148. https://doi.org/10.3846/23450479.2015.1046407

Loh, A. Z., Tan, J. S., Zhang, M. W., \& Ho, R. C. (2017). The global prevalence of anxiety and depressive symptoms among caregivers of stroke survivors. Journal of the American Medical Directors Association, 18(2), 111-116. https://doi.org/10.1016/j.jamda.2016.08.014

Lopez Hartmann, M., Anthierens, S., Van Assche, E., Welvaert, J., Verhoeven, V., Wens, J., \& Remmen, R. (2016). Understanding the experience of adult daughters caring for an ageing parent, a qualitative study. Journal of Clinical Nursing, 25(11-12), 1693-1702. https://doi.org/10.1111/jocn.13195

Losada, A., Márquez-González, M., \& Romero-Moreno, R. (2011). Mechanisms of action of a psychological intervention for dementia caregivers: effects of behavioral activation and modification of dysfunctional thoughts. International Journal of Geriatric Psychiatry, 26(11), 1119-1127. https://doi.org/10.1002/gps.2648

Lund, L., Ross, L., Petersen, M. A., \& Groenvold, M. (2015). The interaction between informal cancer caregivers and health care professionals: a survey of caregivers' experiences of problems and unmet needs. Supportive Care in Cancer, 23(6), 1719-1733. https://doi.org/10.1007/s00520-014-2529-0

Marino, V. R., Haley, W. E., \& Roth, D. L. (2017). Beyond hedonia: A theoretical reframing of caregiver well-being. Translational Issues in Psychological Science, 3(4), 400-409. https://doi.org/10.1037/tps0000134

Márquez-González, M., Losada, A., Izal, M., Pérez-Rojo, G., \& Montorio, I. (2007). Modification of dysfunctional thoughts about caregiving in dementia family caregivers: Description and outcomes of an intervention 
programme. Aging \& Mental Health, 11(6), 616-625.

https://doi.org/10.1080/13607860701368455

Mehri, N., Kinney, J., Brown, S., \& Rajabi Rostami, M. (2021). Informal caregiving and all-cause mortality: A meta-analysis of longitudinal population-based studies. Journal of Applied Gerontology, 40(7), 781-791. https://doi.org/10.1177/0733464819893603

Meichsner, F., Theurer, C., \& Wilz, G. (2019). Acceptance and treatment effects of an internet-delivered cognitive-behavioral intervention for family caregivers of people with dementia: A randomized-controlled trial. Journal of Clinical Psychology, 75(4), 594-613. https://doi.org/10.1002/jclp.22739

Meleis, A. I. (2010). Transitions theory: Middle range and situation specific theories in nursing research and practice. Springer publishing company.

Mogoașe, C., Cobeanu, O., David, O., Giosan, C., \& Szentagotai, A. (2017). Internet-based psychotherapy for adult depression: What about the mechanisms of change? Journal of Clinical Psychology, 73(1), 5-64. https://doi.org/10.1002/jclp.22326

Moore, G. F., Audrey, S., Barker, M., Bond, L., Bonell, C., Hardeman, W., Moore, L., O'Cathain, A., Tinati, T., \& Wight, D. (2015). Process evaluation of complex interventions: Medical Research Council guidance. BMJ, 350:h1258. https://doi.org/10.1136/bmj.h1258

Moss, S. J., Wollny, K., Poulin, T. G., Cook, D. J., Stelfox, H. T., des Ordons, A. R., \& Fiest, K. M. (2021). Bereavement interventions to support informal caregivers in the intensive care unit: a systematic review. BMC Palliative Care, 20(1), 1-10. https://doi.org/10.1186/s12904-021-00763-w

Murauskienè, L. (2021). Lithuania [Chapter]. Oxford University Press. https://doi.org/10.1093/oso/9780198860525.003.0021

Murauskiene, L., Janoniene, R., Veniute, M., van Ginneken, E., Karanikolos, M., \& Organization, W. H. (2013). Lithuania: health system review. World Health Organization. Regional Office for Europe. https://apps.who.int/iris/handle/10665/330306

Navaie-Waliser, M., Spriggs, A., \& Feldman, P. H. (2002). Informal caregiving: differential experiences by gender. Medical Care, 40(12)1249-1259. DOI: 10.1097/01.MLR.0000036408.76220.1F 
Nijboer, C., Triemstra, M., Tempelaar, R., Sanderman, R., \& van den Bos, G. A. (1999). Determinants of caregiving experiences and mental health of partners of cancer patients. Cancer, 86(4), 577-588.

https://doi.org/10.1002/(SICI)1097-0142(19990815)86:4<577::AIDCNCR6>3.0.CO;2-S

Novak, M., \& Guest, C. (1989). Application of a multidimensional caregiver burden inventory. The Gerontologist, 29(6), 798-803.

https://doi.org/10.1093/geront/29.6.798

O’Reilly, D., Rosato, M., Maguire, A., \& Wright, D. (2015). Caregiving reduces mortality risk for most caregivers: a census-based record linkage study. International Journal of Epidemiology, 44(6), 1959-1969. https://doi.org/10.1093/ije/dyv172

Parveen, S., \& Morrison, V. (2012). Predicting caregiver gains: A longitudinal study. British Journal of Health Psychology, 17(4), 711-723. https://doi.org/10.1111/j.2044-8287.2012.02067.x

Pearlin, L. I., Mullan, J. T., Semple, S. J., \& Skaff, M. M. (1990). Caregiving and the stress process: An overview of concepts and their measures. The Gerontologist, 30(5), 583-594. https://doi.org/10.1093/geront/30.5.583

Pendergrass, A., Becker, C., Hautzinger, M., \& Pfeiffer, K. (2015). Dementia caregiver interventions: A systematic review of caregiver outcomes and instruments in randomized controlled trials. International Journal of Emergency Mental Health and Human Resilience, 17(2), 459-468. DOI:10.4172/1522-4821.1000195

Perkins, M., Howard, V. J., Wadley, V. G., Crowe, M., Safford, M. M., Haley, W. E., Howard, G., \& Roth, D. L. (2013). Caregiving strain and all-cause mortality: evidence from the REGARDS study. Journals of Gerontology Series B: Psychological Sciences and Social Sciences, 68(4), 504-512. doi: $10.1093 /$ geronb/gbs084

Pignatiello, G. A., Martin, R., Kraus, N., Gutierrez, A., Cusick, R., \& Hickman, R. L. (2021). Sleep interventions for informal caregivers of persons with dementia: A systematic review. Western Journal of Nursing Research, 01939459211019033. https://doi.org/10.1177/01939459211019033

Pihlaja, S., Lahti, J., Lipsanen, J. O., Ritola, V., Gummerus, E.-M., Stenberg, J.-H., \& Joffe, G. (2020). Scheduled telephone support for internet cognitive behavioral therapy for depression in patients at risk for dropout: pragmatic 
randomized controlled trial. Journal of Medical Internet Research, 22(7), e15732. doi:10.2196/15732

Pinquart, M., \& Sörensen, S. (2003). Differences between caregivers and noncaregivers in psychological health and physical health: a meta-analysis. Psychology and Aging, 18(2), 250-267. https://doi.org/10.1037/08827974.18.2.250

Pinquart, M., \& Sörensen, S. (2005). Ethnic differences in stressors, resources, and psychological outcomes of family caregiving: A meta-analysis. The Gerontologist, 45(1), 90-106. https://doi.org/10.1093/geront/45.1.90

Pinquart, M., \& Sörensen, S. (2006a). Gender differences in caregiver stressors, social resources, and health: An updated meta-analysis. The Journals of Gerontology Series B: Psychological Sciences and Social Sciences, 61(1), P33-P45. https://doi.org/10.1093/geronb/61.1.P33

Pinquart, M., \& Sörensen, S. (2006b). Helping caregivers of persons with dementia: which interventions work and how large are their effects? International Psychogeriatrics, 18(4), 577-595. doi:10.1017/S1041610206003462

Ploeg, J., Markle-Reid, M., Valaitis, R., McAiney, C., Duggleby, W., Bartholomew, A., \& Sherifali, D. (2017). Web-based interventions to improve mental health, general caregiving outcomes, and general health for informal caregivers of adults with chronic conditions living in the community: rapid evidence review. Journal of Medical Internet Research, 19(7), e263. doi:10.2196/jmir.7564

Plöthner, M., Schmidt, K., De Jong, L., Zeidler, J., \& Damm, K. (2019). Needs and preferences of informal caregivers regarding outpatient care for the elderly: a systematic literature review. BMC Geriatrics, 19(1), 1-22. https://doi.org/10.1186/s12877-019-1068-4

Poškutè, V., Kazlauskaite, R., \& Matonytė, I. (2021). Stakeholder collaboration in long-term care of older people in Lithuania. Health \& Social Care in the Community, 30(1), 193-202. https://doi.org/10.1111/hsc.13389

Prevo, L., Hajema, K., Linssen, E., Kremers, S., Crutzen, R., \& Schneider, F. (2018). Population characteristics and needs of informal caregivers associated with the risk of perceiving a high burden: a cross-sectional study. INQUIRY: The Journal of Health Care Organization, Provision, and Financing, 55, 0046958018775570. https://doi.org/10.1177/0046958018775570 
Pristavec, T. (2019). The caregiving dyad: Do caregivers' appraisals of caregiving matter for care recipients' health? Archives of Gerontology and Geriatrics, 82, 50-60. https://doi.org/10.1016/j.archger.2019.01.020

Quinn, C., \& Toms, G. (2019). Influence of positive aspects of dementia caregiving on caregivers' well-being: A systematic review. The Gerontologist, 59(5), e584-e596. https://doi.org/10.1093/geront/gny168

Rafnsson, S. B., Shankar, A., \& Steptoe, A. (2017). Informal caregiving transitions, subjective well-being and depressed mood: Findings from the English Longitudinal Study of Ageing. Aging \& Mental Health, 21(1), 104-112. https://doi.org/10.1080/13607863.2015.1088510

Reinhard, S. C., Feinberg, L. F., Choula, R., \& Houser, A. (2015). Valuing the invaluable: 2015 update. Insight on the Issues, 104, 89-98.

https://castor.house.gov/uploadedfiles/aarp_valuing_the_invaluable_2015_u pdate.pdf

Revenson, T., Griva, K., Luszczynska, A., Morrison, V., Panagopoulou, E., Vilchinsky, N., \& Hagedoorn, M. (2016). Caregiving in the illness context. Springer.

Roth, D. L., Fredman, L., \& Haley, W. E. (2015). Informal caregiving and its impact on health: A reappraisal from population-based studies. The Gerontologist, 55(2), 309-319. https://doi.org/10.1093/geront/gnu177

Rozental, A., Forsström, D., Tangen, J. A., \& Carlbring, P. (2015). Experiences of undergoing Internet-based cognitive behavior therapy for procrastination: A qualitative study. Internet Interventions, 2(3), 314-322.

https://doi.org/10.1016/j.invent.2015.05.001

Rozental, A., Kothari, R., Wade, T., Egan, S., Andersson, G., Carlbring, P., \& Shafran, R. (2020). Reconsidering perfect: a qualitative study of the experiences of internet-based cognitive behaviour therapy for perfectionism. Behavioural and Cognitive Psychotherapy, 48(4), 432-441. https://doi.org/10.1017/S1352465820000090

Saunders, J. B., Aasland, O. G., Babor, T. F., De la Fuente, J. R., \& Grant, M. (1993). Development of the alcohol use disorders identification test (AUDIT): WHO collaborative project on early detection of persons with harmful alcohol consumption-II. Addiction, 88(6), 791-804. https://doi.org/10.1111/j.1360-0443.1993.tb02093.x 
Sawan, M. J., Wennekers, D., Sakiris, M., \& Gnjidic, D. (2021). Interventions at hospital discharge to guide caregivers in medication management for people living with dementia: a systematic review. Journal of General Internal Medicine, 36, 1371-1379. https://doi.org/10.1007/s11606-020-06442-5

Schaeuffele, C., Schulz, A., Knaevelsrud, C., Renneberg, B., \& Boettcher, J. (2021). CBT at the crossroads: The rise of transdiagnostic treatments. International Journal of Cognitive Therapy, 14, 86-113. https://doi.org/10.1007/s41811-020-00095-2

Schulz, R., \& Sherwood, P. R. (2008). Physical and mental health effects of family caregiving. Journal of Social Work Education, 44(sup3), 105-113. https://doi.org/10.5175/JSWE.2008.773247702

Semonella, M., Vilchinsky, N., Dakel, R., Biliunaite, I., Pietrabissa, G., \& Andersson, G. (2020). SOSteniamoci: An internet-based intervention to support informal caregivers. PSYCHOBIT. http://ceur-ws.org/Vol2730/paper13.pdf

Sherifali, D., Ali, M. U., Ploeg, J., Markle-Reid, M., Valaitis, R., Bartholomew, A., Fitzpatrick-Lewis, D., \& McAiney, C. (2018). Impact of internet-based interventions on caregiver mental health: systematic review and metaanalysis. Journal of Medical Internet Research, 20(7), e10668. doi:10.2196/10668

Skivington, K., Matthews, L., Simpson, S. A., Craig, P., Baird, J., Blazeby, J. M., Boyd, K. A., Craig, N., French, D. P., \& McIntosh, E. (2021). A new framework for developing and evaluating complex interventions: update of Medical Research Council guidance. BMJ, 374 :n2061. https://doi.org/10.1136/bmj.n2061

Smoktunowicz, E., Barak, A., Andersson, G., Banos, R. M., Berger, T., Botella, C., Dear, B. F., Donker, T., Ebert, D. D., Hadjistavropoulos, H., Hodgins, D. C., Kaldo, V., Mohr, D. C., Nordgreen, T., Powers, M. B., Riper, H., Ritterband, L. M., Rozental, A., Schueller, S. M., Titov, N., Weise, C., \& Carlbring, P. (2020). Consensus statement on the problem of terminology in psychological interventions using the internet or digital components. Internet Interventions, 21, 100331. https://doi.org/10.1016/j.invent.2020.100331

Smyth, C., Blaxland, M., \& Cass, B. (2011). 'So that's how I found out I was a young carer and that I actually had been a carer most of my life'. Identifying 
and supporting hidden young carers. Journal of Youth Studies, 14(2), 145160. https://doi.org/10.1080/13676261.2010.506524

Spencer, L., Potterton, R., Allen, K., Musiat, P., \& Schmidt, U. (2019). Internetbased interventions for carers of individuals with psychiatric disorders, neurological disorders, or brain injuries: Systematic review. Journal of Medical Internet Research, 21(7), e10876. doi:10.2196/10876

Spitzer, R. L., Kroenke, K., Williams, J. B., \& Löwe, B. (2006). A brief measure for assessing generalized anxiety disorder: the GAD-7. Archives of Internal Medicine, 166(10), 1092-1097. doi:10.1001/archinte.166.10.1092

Topp, C. W., Østergaard, S. D., Søndergaard, S., \& Bech, P. (2015). The WHO-5 Well-Being Index: a systematic review of the literature. Psychotherapy and Psychosomatics, 84(3), 167-176. https://doi.org/10.1159/000376585

Townsend, A., Noelker, L., Deimling, G., \& Bass, D. (1989). Longitudinal impact of interhousehold caregiving on adult children's mental health. Psychology and Aging, 4(4), 393-401. https://doi.org/10.1037/0882-7974.4.4.393

Tur-Sinai, A., Teti, A., Rommel, A., Hlebec, V., \& Lamura, G. (2020). How many older informal caregivers are there in Europe? Comparison of estimates of their prevalence from three european surveys. International Journal of Environmental Research and Public Health, 17(24), 9531. https://doi.org/10.3390/ijerph17249531

van Groenou, M. I. B., \& De Boer, A. (2016). Providing informal care in a changing society. European Journal of Ageing, 13, 271-279. https://doi.org/10.1007/s10433-016-0370-7

Van't Leven, N., de Lange, J., van der Ploeg, E. S., \& Pot, A. M. (2018). Working mechanisms of dyadic, psychosocial, activating interventions for people with dementia and informal caregivers: a qualitative study. Clinical Interventions in Aging, 13, 1847-1857. doi: 10.2147/CIA.S160363

Verbakel, E., Tamlagsrønning, S., Winstone, L., Fjær, E. L., \& Eikemo, T. A. (2017). Informal care in Europe: findings from the European Social Survey (2014) special module on the social determinants of health. The European Journal of Public Health, 27(suppl_1), 90-95.

https://doi.org/10.1093/eurpub/ckw229 
Vlachantoni, A., Evandrou, M., Falkingham, J., \& Robards, J. (2013). Informal care, health and mortality. Maturitas, 74(2), 114-118.

https://doi.org/10.1016/j.maturitas.2012.10.013

Vlaescu, G., Alasjö, A., Miloff, A., Carlbring, P., \& Andersson, G. (2016). Features and functionality of the Iterapi platform for internet-based psychological treatment. Internet Interventions, 6, 107-114. https://doi.org/10.1016/j.invent.2016.09.006

Wasilewski, M. B., Stinson, J. N., \& Cameron, J. I. (2017). Web-based health interventions for family caregivers of elderly individuals: a scoping review. International Journal of Medical Informatics, 103, 109-138. https://doi.org/10.1016/j.ijmedinf.2017.04.009

Weathers F, Blake D, Schnurr P, Kaloupek D, Marx B, Keane T. The life events checklist for DSM-5 (LEC-5) - Standard. National Center for PTSD. 2013. Available at: https://www.ptsd.va.gov/

Webber-Ritchey, K. J., Aquino, E., Ponder, T. N., Lattner, C., Soco, C., Spurlark, R., \& Simonovich, S. D. (2021). Recruitment strategies to optimize participation by diverse populations. Nursing Science Quarterly, 34(3), 235243. https://doi.org/10.1177/08943184211010471

Wiegelmann, H., Speller, S., Verhaert, L.-M., Schirra-Weirich, L., \& WolfOstermann, K. (2021). Psychosocial interventions to support the mental health of informal caregivers of persons living with dementia-a systematic literature review. BMC Geriatrics, 21, 1-17. https://doi.org/10.1186/s12877021-02020-4

Wright, J. H., Brown, G. K., Thase, M. E., \& Basco, M. R. (2017). Learning cognitive-behavior therapy: An illustrated guide. American Psychiatric Pub.

Yates, M. E., Tennstedt, S., \& Chang, B.-H. (1999). Contributors to and mediators of psychological well-being for informal caregivers. The Journals of Gerontology Series B: Psychological Sciences and Social Sciences, 54(1), P12-P22. https://doi.org/10.1093/geronb/54B.1.P12

Žalimienè, L., Blažienè, I., \& Junevičienè, J. (2020). What type of familialism is relevant for Lithuania? The case of elderly care. Journal of Baltic Studies, 51(2), 159-178. https://doi.org/10.1080/01629778.2020.1746368 
Zarit, S. H., Todd, P. A., \& Zarit, J. M. (1986). Subjective burden of husbands and wives as caregivers: A longitudinal study. The Gerontologist, 26(3), 260266. https://doi.org/10.1093/geront/26.3.260

Zwar, L., König, H.-H., \& Hajek, A. (2020). Psychosocial consequences of transitioning into informal caregiving in male and female caregivers: findings from a population-based panel study. Social Science \& Medicine, 264, 113281. https://doi.org/10.1016/j.socscimed.2020.113281 


\section{Studies}

The studies associated with this thesis have been removed for copyright reasons. For more details about these see:

https://doi.org/10.3384/9789179291877 
213. HAGMAN, WILLIAM. When are nudges acceptable? Influences of beneficiaries, techniques, alternatives and choice architects. 2018. ISBN: 978-91-7685-160-9

214. RAHM, LINA. Educational imaginaries: a genealogy of the digital citizen. 2019. ISBN: 978-91-7685-158-6

215. HALVARSSON LUNDQVIST, AGNETA. Learning Dynamics of Workplace Development Programmes. Studies in Swedish national programmes. 2019. ISBN: 978-91-7685-124-1

216. HOLMQVIST LARSSON, MATTIAS. Rupture and Repair in the Working Alliance: Relation to Psychotherapy Outcome and Within-Session Interaction. 2019. ISBN: 978-91-7685-111-1

217. LINDQVIST, HENRIK. Student teachers' and beginning teachers' coping with emotionally challenging situations. 2019. ISBN: 978-91-7685-078-7

218. GRÖNLUND, AGNETA. Återkoppling i analoga och digitala klassrum. Spänningsfyllda verksamheter i samhällskunskapsundervisning. 2019. ISBN: 978-91-7685-074-9

219. ÅKERBLOM, ERIKA. Utbildning och hälsa i nationens intresse.

Styrningsteknologier och formering av en förädlad befolkning. 2019. ISBN: 978-91-7685-053-4220.

220. ÖSTERBORG WIKLUND, SOFIA. Folkbildning i global (o)rättvisa. Makt och motstånd i folkhögskolans internationalisering och transnationella kurser. 2019. ISBN: 978-91-7519-002-0

221. DAHLIN, MATS. Development and evaluation of an internet-based treatment for generalized anxiety disorder. An acceptance-based approach. 2020. ISBN: 978-91-7929-793-0

222. ERIKSSON, ELISABETH. Återkoppling i lågstadieklassrum. 2020. ISBN: 978-91-7929-769-5

223. KÖPSÉN, JOHANNA. Knowledge in VET curricula and power in society and labour market. Policy and practice: demands-based and employer-driven Swedish higher vocational education. 2020. ISBN: 978-91-7929-768-8

224. SJÖGREN, BJÖRN. Bystander behaviors in peer victimization: Associations with moral disengagement, efficacy beliefs, and student-teacher relationship quality. 2021. ISBN: 978-91-7929-728-2 
225. PERSSON-ASPLUND, ROBERT. Learning how to recover from stressrelated disorders via internet-based interventions. 2021. ISBN: 978-91-7929$722-0$

226. UCKELSTAM, CARL-JOHAN. Looking into the Future: How to Use Advanced Statistical Methods for Predicting Psychotherapy Outcomes in Routine Care. 2021. ISBN: 978-7929-709-1

227. BERG, MATILDA. JUST KNOW IT. The role of explicit knowledge in internet-based cognitive behaviour therapy for adolescents. 2021.

ISBN: 978-91-7929-687-2

228. FERM, LISA. Vocational Students' Agency in Identity Formation as Industrial Workers. 2021. ISBN: 978-91-7929-653-7

229. ANDERSSON, ULRIKA. Framåtsyftande bedömning i tidig läsundervisning. Teori och praktik. 2021. ISBN: 978-91-7929-646-9

230. SVEIDER, CECILIA. Representationer av tal i bråkform. En studie av matematikundervisning på mellanstadiet. 2021. ISBN: 978-91-7929-607-0

231. ARNELL, SOFIE. Elevers möten med matematik. En studie om elevers möten med matematik i förskoleklass och årskurs 1. 2021. ISBN: 978-917929-605-6

232. MÅRTENSSON, ÅSA. Yrkesutbildning på gränsen mellan skola och arbetsliv - en intervjustudie om yrkeslärares och handledares arbete med arbetsplatsförlagt lärande. 2021. ISBN: 978-91-7929-047-4

233. KÄLL, ANTON. Internet-based interventions for loneliness - Efficacy and latent psychopathological profiles of treatment seekers. 2021. ISBN: 978-917929-057-3

234. STRINDBERG, JOAKIM. "Why DO We Even Bully?” Exploring the Social Processes of Bullying in Two Swedish Elementary Schools. 2021.

ISBN: 978-91-7929-097-0

235. AMINOFF, CHRISTINA. Skriftspråkliga handlingar i förskoleklass och årskurs 1. 2021. ISBN: 978-91-7929-109-9

236. BJÄREHED, MARLENE. The Association Between Moral Disengagement and Bullying in Early Adolescence. 2022. ISBN: 978-91-7929-127-3

237. LINDEGAARD, TOMAS. Internet-based treatment of depression and anxiety among migrants and refugees in Sweden. 2022. ISBN: 978-91-7929-139-6

238. SKAGENHOLT, MIKAEL. Neurocognitive Foundations of Child and Adult Number Processing. Neural Correlates and Functional Circuits Across Typical Development. 2022. ISBN: 978-91-7929-158-7 


\section{FACULTY OF ARTS AND SCIENCES}

Linköping Studies in Arts and Sciences No. 831

Linköping Studies in Behavioural Science No. 239

Department of Behavioural Sciences and Learning

At the Faculty of Arts and Sciences at Linköping University, research and doctoral studies are carried out within interdisciplinary research environments, often addressing broad problem areas.

Linköping Studies in Arts and Sciences is the Faculty's own series for publishing research. This thesis comes from the Division of Psychology at the Department of Behavioural Sciences and Learning.

Linköping University

SE-581 83 Linköping, Sweden

www.liu.se 